\title{
Somogy megye madárfaunája (Aves)
}

\author{
Purger J. Jenó \& Fenyớsi LÁsZló
}

\begin{abstract}
PURger J. J. \& FenYôsi L.: The avian fauna of Somogy county, Hungary(Aves)
Abstract: No comprehensive work has been written about the avian fauna of Somogy county. Research activities have concentrated mostly on Lake Balaton, the Kis-Balaton area, the Boronka region, lake Baláta, the juniper woodland at Barcs and the Dráva lowlands. The majority of the articles published are short communications; lengthier publications, or recently even bibliographies, have been produced only about the aforementioned, now protected areas. Most of these data are quite different from each other in many respects, thus their collation or summarisation faces difficulties. The aim of this study has been to collect and survey the works produced on the ornithofauna of the county, and to compile a species-list. It was established that out of the 373 species occurring in Hungary, there is evidence for the presence of 284 in Somogy county. Earlier results and, most of all, deficiencies revealed will hopefully provide stimulation for launching the study of the bird fauna in less researched areas, as well as for widening our knowledge about species occurring in this county.
\end{abstract}

\section{Bevezetés}

A magyar ornitológiában a mai napig mérföldkőnek számít SCHENK (1918) munkája (Fauna Regni Hungariae), melyben részletes áttekintést ad a madártan fejlődésének történetéról és a Magyar Birodalom területén elóforduló madárfajokról. Az irodalomjegyzékbool kiderül, hogy egy évszázaddal ezelótt Schenknek már közel 2000 cikket kellet átnéznie, hogy az említett munkát megírja. Nem csoda, hogy az irodalmi forrásokra csak a történeti áttekintés során hivatkozott. Már ô is a kompromisszumot kereshette, hiszen a madárfajok tárgyalásánál nem említhette meg a megfigyelések minden egyes lelóhelyét, dátumát. Ezt csak a ritkábban elóforduló fajok esetében tette.

Somogy megye madárfaunájáról még nem íródott összefoglaló jellegú munka, így kiindulópontnak akár SCHENk (1918) munkáját is vehetjük. A szerző ugyanis több faj elófordulása kapcsán Somogy megyei lelóhelyre vagy a megyére utal. Ismereteinket bibliográfiák (pl. RÉTHY 1980) tanulmányozásával és a könyvtárakban végzett munkával gyarapíthattuk.

A magyar ornitológia és a magyar tudomány hírnevét már több, mint egy évszázada öregbíti az Aquila. Mint Herman Ottó idejében, hasábjain ma is évról-évre megjelennek a legújabb madártani megfigyelések, kutatások eredményei. Nem hagyhattuk figyelmen kívül a többi folyóiratot sem (pl. Állattani Közlemények, Dunántúli Dolgozatok Természettudományi Sorozata, Kócsag, Somogyi Almanach, Somogyi Múzeumok Közleményei), hiszen azokban is található szép számban a megye madaraira vonatkozó közlemény. Az utóbbi évtizedekben az ornitológia térhódításának lehettünk tanúi, ami a madármegfigyelők számának növekedését eredményezte. Ók elsósorban a Madártani Tájékoztatóban, majd később a Túzokban és az Anserban jelentették meg közleményeiket. Ez a fellendülés a mellékelt irodalomjegyzéken is megmutatkozik, 
hiszen a cikkek, több mint a fele a nyolcvanas kilencvenes években íródott. Az és szembetúnô, hogy az 50-es évekig a rövid közlemények domináltak. Késóbb pedig már hosszabb cikkek, tanulmányok is íródtak a Balaton déli partja (pl. HAVRANEK et al. 1995a; Keve 1973, 1975, 1978; SzABÓ 1996a), a Boronka mellék (pl. MAJER 1992a) a Baláta-tó (pl. KASZA \& MARIÁN 200l; MAjER 1992b; MARIÁN 1957; MARIÁN \& PUSKás 1985), a Barcsi Borókás (pl. FenYÖSI 1993a, 2000; KárṔ́TI 1979) és a Dráva mente (pl. BANK 1998; FeNYốSI 1996, PURGER 1998a) madárvilágáról. A madártani kutatások a megye egyes kiemelt, ma már védett területeire összpontosultak. A vizsgálatok zöme faunisztikai jellegú, így e tekintetben nem volt szükség szelekcióra. Ennek ellenére a kompromisszumos megoldásoktól és a válogatástól mi sem mentesülhettünk, hiszen a terület nagysága és körülhatároltsága (pl. a Balaton víztükrén megfigyelt fajok) sok fejtörést okozott. Figyelmünket az sem kerülhette el, hogy a Zselic és Külső-Somogy madárvilágáról szinte semmit sem tudunk.

Munkánk elsődleges célja a Somogy megyében előfordult vagy előforduló madárfajok listájának elkészítése volt. A fajok, családok, rendek tudományos és magyar nevei valamint sorrendje MAGYAR et al. (1998) munkája alapján készült, hogy a megye faunája bármikor összevethetố legyen a magyar névjegyzékkel. A fajok mellett a fontosabb irodalmi forrásokat is feltüntettük (abc sorrendben).

\section{Somogy megye madarainak jegyzéke}

AVES - MADARAK

GAVIIFORMES - BÚVÁRALAKÚAK

Gaviidae - Búvárfélék

I. Gavia stellata (Pontoppidan, 1763) Északi búvár - BANK 1998; FENYósı 1996, 1997, 2000; HaDARICS 1998a; HAVRANEK 1996b; HaVranek et. al. 1995a; MolnÁR 1984b; NAGY \& PTNTÉR I994; SCHENK 1918.

2. Gavia arctica (Linnaeus, 1758) - Sarki búvár - BANK 1998; FENYŐSI 1997, 1996; Hadarics 1997a; HaVRANEK 1996b; HaVRANEK et. al. 1995a; KEVE 1973, 1978; MOLNÁR 1982c, 1982h, 1984b, 1985, 1988b; NAGY \& PinTÉr 1994.

3. Gavia immer (Brünnich, 1764) - Jeges búvár - NAGY \& PINTÉr 1994.

PODICIPEDIFORMES - VÖCSÖKALAKÚAK

Podicipedidae - Vöcsökfélék

4. Tachybaptus ruficollis (Pallas, I764) - Kis vöcsök - BANK 1998; FENYÖSI 1993a, 1996, 1997, 1999b, 2000; HaVRANeK 1996b; Majer 1992a, 1992b; MARIÁN 1957, 1959; MARIÁN \& PusKás 1985; KASZA \& MARIÁN 2001; KÁrPÁtI 1979, 1980; KeVE 1973, 1978; NAGY \& Pintér 1994, Purger 1998a; Tevely 1996; TÖMÖSVÁRY et. al. 2000.
5. Podiceps cristatus (Linnaeus, 1758) - Búbos vöcsök - BANK 1998; FENYŐSI 1993a, 1996, 1997, 1999b, 2000; HAVRANEK 1996b; HAVRANEK et. al. 1995a; KASZA \& MARIÁN 2001; KárpátI 1979; KeVe 1973, 1978; Majer 1992a; Marián \& Puskás 1985; NaGY \& Pintér I994, PURGER 1998a.

6. Podiceps grisegena (Boddaert, 1783) Vörösnyakú vöcsök - FENYôsı 1996, 1997; HAVRANEK 1996b; HAVRANEK et. al. 1995a; KASZA \& MARLÁN 2001; KEVE 1973, 1978; Molnár 1988b; NAGY \& Pintér 1994.

7. Podiceps auritus (Linnaeus, 1758) - Füles vöcsök - HAVRANEK 1996b; MME NOMENClator BizotTSÁG 1998; SCHENK 1918.

8. Podiceps nigricollis C. L. Brehm, 1831 - Feketenyakú vöcsök - FENYÖSI 1997; HAVRANEK 1996b; HAVRANEK et. al. 1995a; KASZA \& Marián 200I; KeVe 1973, 1978; Majer 1992a, 1992b; MARĹ́N 1957, 1958b, 1959; NAGY \& PINTÉR 1994.

\section{PELECANIFORMES - GÖDÉNYALAKÚAK}

Phalacrocoracidae - Kárókatonafélék

9. Phalacrocorax carbo (Linnaeus, 1758) Kárókatona - BANK 1998; FENYŐsI 1993a, 1996, 1997, 2000; HavraneK 1996b; HAVRANEK et. al. 1995a; KASZA \& MARIÁN 2001; KeVe 1973, 1975, 1978; Majer 1992a; 


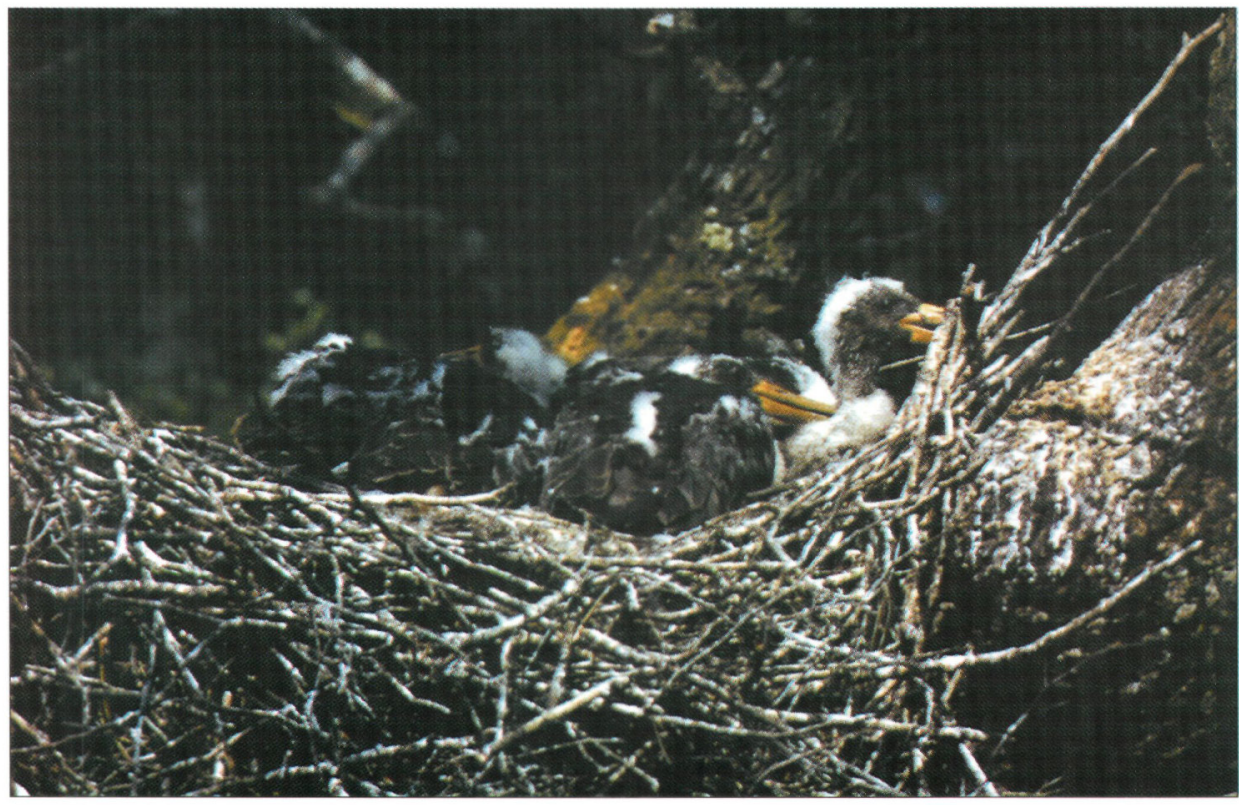

1. ábra: Fekete gólya (Ciconia nigra) Fotó: Fenyősi L.

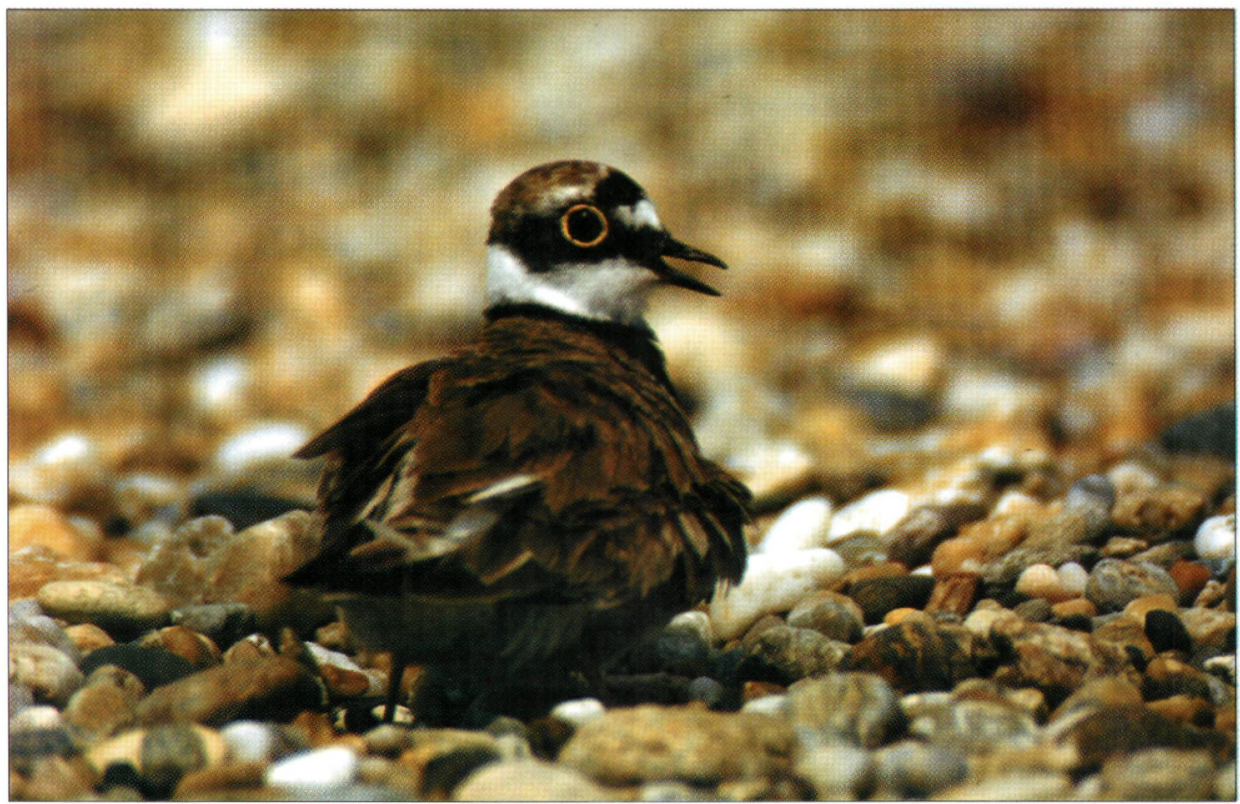

2. ábra: Kis lile (Charadrius dubius) Fotó: Fenyôsi L. 


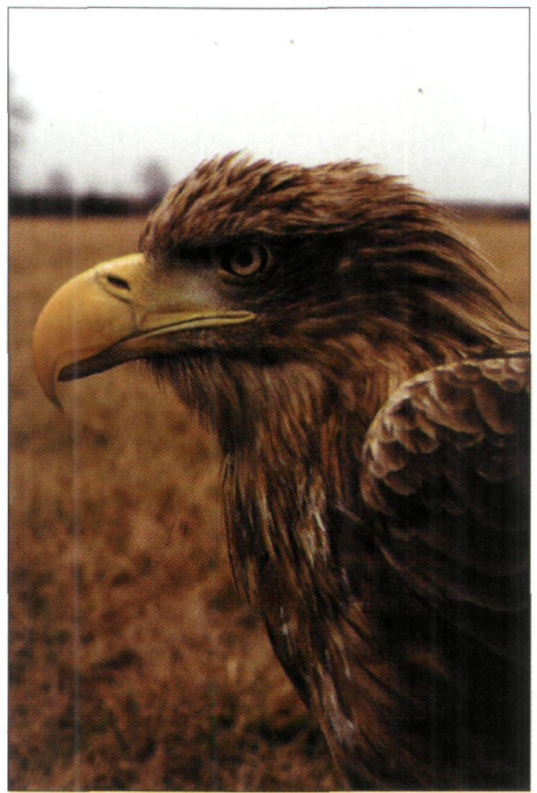

3. ábra: Rétisas (Haliaeetus albicilla) Fotó: Fenyósi L.

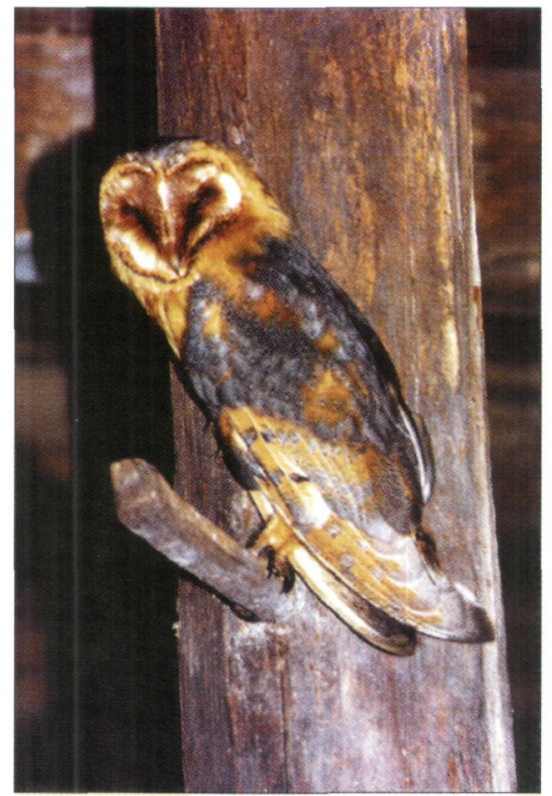

4. ábra: Gyöngybagoly (Tyto alba) Fotó: Fenyősi L. 
Purger 1998a; Schenk 1918; Szabó 1996b; SZÁRI 1996; TEVELY 1996.

10. Phalacrocorax pygmeus (Pallas, 1773) Kis kárókatona - HADARICS I998a; HAJEK 1955.

\section{Pelecanidae - Gödényfélék}

11. Pelecanus onocrotalus Linnaeus, 1758 . Rózsás gödény - KEVE 1978; SCHENK 1918.

\section{CICONIIFORMES - GÓLYAALAKÚAK}

\section{Ardeidae - Gémfélék}

12. Botaurus stellaris (Linnaeus, 1758) - Bölömbika - FENYÖSI 1993a, 2000; HAVRANEK 1996b; KASZA \& MARLÁN 2001; KeVE 1973, 1978; MAJER 1992b; MARLÁN 1957, 1958a, 1959; NAGY \& PINTÉR 1994.

13. Ixobrychus minutus (Linnaeus, 1766) Törpegém - BANK 1998; FENYÓsı 1993a, 1996, 1997, 2000; HavraneK 1996b; Kasza \& Marián 2001; Kárpáti 1979, 1980; Keve 1973, 1978; MAJER 1992a, 1992b; MARLÁN 1957, 1959; MARIÁN \& PUSKÁS 1985; NAGY \& Pintér 1994, Purger 1998a; TeVely 1996.

14. Nycticorax nycticorax (Linnaeus, 1758) Bakcsó - BALI 1983; BANK1998; FENYŐSI 1993a, 1996, 1997, 2000; FÖLDVÁRY 1929; HAVRANEK 1996b; KASZA \& MARIÁN 2001; KÁRPÁti 1979, 1980; Keve 1973, 1975, 1978; Majer 1992a, 1992b; Marián 1957, 1958b, 1959; MARIÁN \& PUSKÁS 1985; MOLNÁR 1982a; NAGY \& Pintér 1994, Purger 1998a; SÁrA 1970a.

15. Ardeola ralloides (Scopoli, 1769) Üstökösgém - FENYÖSI 2000; HAVRANEK 1996b; KASZA \& MARIÁN 2001; KÁRPÁTI 1979, 1980; KeVE 1973, 1975, 1978; MAJER 1992a; NAGY \& PINTÉR 1994; SCHENK 1918.

16. Egretta garzetta (Linnaeus, 1766) - Kis kócsag - BANK 1998; FENYÓsı 1996, 1997; HaVRANEK 1996b; KASZA \& MARLÁN 2001; Keve 1973, 1975, 1978; Majer 1992a; NAGY \& Pintér 1994, Purger 1998a; SÁra 1970a; SCHENK 1918.

17. Egretta alba (Linnaeus, 1758) - Nagy kócsag - BANK 1998; FENYỐSI 1993a, 1996, 1997, 2000; FENYÓSI \& STIX 1996; GYÖRGYPÁL 1978; HaVRANEK 1996b; HaVRANEK et. al. 1995a; KASZA \& MARIÁN 2001; KÁRPÁTI 1979, 1980; KEVE 1973, 1975, 1978; MAJER 1992a, 1992b; MarIáN \& PuSKÁs 1985; M.O.K. 1895; Nagy \& Pintér 1994, Purger 1998a; SCHENK 1918; TeVELY 1996.

18. Ardea cinerea Linnaeus, 1758 - Szürke gém - BANK1 998; FENYÓSI 1993a, 1996, 1997, 2000; FENYÖSI \& STIX 1996; FÖLDVÁRY 1929; HAVRANEK 1996b; HaVRANEK et. al. 1995a;
KASZA \& MARIÁN 2001; KÁRPÁTI 1979, 1980; KeVe 1973, 1975, 1978; MAJER 1992a, 1992b; MARIÁN 1957, 1958a, 1958b, 1959; MARIÁN \& PUSKÁS 1985; MOLNÁR 1982a; NAGY \& PINTÉR 1994, PURGER 1998a; SÁrA 1970a; TeVELX 1996.

19. Ardea purpurea Linnaeus, 1766 - Vörös gém - BANK 1998; FENYÓSI 1993a, 1996, 1997, 2000; HaVRaneK 1996b; HaVRaneK et. al. I995a; KASZA \& MARIÁN 2001; KÁRPÁTI 1979, 1980; KeVE 1973, 1975, 1978; MAJER 1992a, 1992b; MARIÁN 1957, 1959; MARIÁN \& PUSKÁS 1985; MOLNÁR 1982a; NAGY \& PinTÉR 1994; Purger 1998a; Sára 1970a; Tevely 1996.

\section{Ciconiidae - Gólyafélék}

20. Ciconia nigra (Linnaeus, 1758) - Fekete gólya - BANK 1998; FENYÓSI 1993a, 1996, 1998c, 1997, 2000; FENYÖSI \& STIX 1995; FILOTÁS 1996; GYÖRGYPÁL 1978; HAVRANEK 1995, 1996b; HAVRANEK et. al. 1995a; HORVÁTH et al 2001; KASZA \& MARIÁN 2001; KÁRPÁti 1979, 1980; KEVE 1951, 1973, 1978; MAJER 1992a, 1992b; MARIÁN 1957, 1958a, 1958b, 1959; Marián \& Puskás 1985; NagY \& Pintér 1994; Pintér 1993; PURGer 1998a; TEVELY 1996; TÖMÖSVÁRY 1982b; VASVÁRI 1937.

21. Ciconia ciconia (Linnaeus, 1758) - Fehér gólya - BALI 1983; BANK 1998; BARTOS 1906b; FENYŌSI 1993a, 1994e, 1996, 1998a, 1997, 2000; FENYÔSI \& HORVÁTH 2000a; FILOTÁS 1996; HaVRANEK 1996b; HUNYADVÁRY 1979; JAKAB 1989, 1991, 1992a, 1992b, 1993; KASZA 1987; KÁRPÁTI 1979; KEVE 1973, 1975, 1978; LÁSZLÓ et. al. 1996; MAJER 1992a; MARIÁN 1956, 1958a; MARIÁN \& PUSKÁS 1985; NAGY I 991; NAGY \& Pintér 1994; Novotny et. al. 1995; PURGER 1998a; SÁrA 1970a, 1970b; UJVÁRY 1917.

\section{Threskiornithidae - Ibiszfélék}

22. Plegadis falcinellus (Linnaeus, 1766) Batla - FöldVÁRY 1929; KEVE I973, 1978; Molnár 1985; Nagy \& Pintér 1994; SCHENK 1918.

23. Platalea leucorodia Linnaeus, 1758 Kanalasgém - AGÁRDI 1935; HAVRANEK 1995, 1996b; HAVRANEK et. al. 1995a; KASZA \& MARLÁN 2001; KEVE 1973, 1975, 1978; MAJER 1992a; NAGY \& PinTÉr 1994; SCHENK 1918.

ANSERIFORMES - LÚDALAKÚAK

\section{Anatidae - Récefélék}

24. Cygnus olor (J. F. Gmelin, 1789) - Bütykös hattyú - BANKI998; BANKOVICS 1985; FENYÖSI 1996, 1999a, 1997, 1999b, 2000; HAVRANEK 1995, 1996b; HAVRANEK et. al. 
1995a; KASZA \& MARIÁN 2001; KeVE 1978; MOLNÁr 1987b; NAGY \& PINTÉr I994, PURGER 1998a; TILESCH 1986c.

25. Cygnus cygnus (Linnacus, 1758) - Énekes hattyú - ANONYMUS 1906; KÁRPÁTI 1979; KeVE 1978; Molnár 1987b; NAGY \& Pintér 1994; SCHENK 1918; SZALAI 1955.

26. Anser fabalis (Latham, 1787) - Vetési lúd - BANK 1998; CHERNel 1921; FENYÖSI 1993a, 1996, 1997, 1999b, 2000; HAVRANEK 1996a, 1996b; HAVRANEK et. al. 1995a; KASZA \& MARIÁN 2001; KÁRPÁTI 1979; KEVE 1973, 1975, 1978; MARIÁN \& PUSKás 1985; PURGer 1998a; SZATORI 1984.

27. Anser brachyrhynchus Baillon, 1833 - Rövidcsőrú lúd - HAVRANEK 1996a; KEVE 1978.

28. Anser albifrons (Scopoli, 1769) - Nagy lilik - BANK 1998; FENYÓsI 1993a, 1996, 1997, 1999b, 2000; HAVRANEK 1995, 1996a, 1996b; HAVRANEK et. al. 1995a; KÁRPÁTI 1979; KEVE 1973, 1975, 1978; MARIÁN \& PUSKÁs 1985; Purcier 1998a; Schenk 1918.

29. Anser erythropus (Linnaeus, 1758) - Kis lilik - FenYósı 1996, 1997; HaVRaneK 1995, 1996b; MOLNÁr 1982c; NAGY \& Pintér 1994.

30. Anser anser (Linnaeus, 1758) - Nyári lúd - BANK 1998; FENYósi 1996, 1997, 1999b, 2000; Havranek 1995, 1996a; Havranek et. al. 1995a; KASZA \& MARIÁN 2001; KEVE 1973, 1975, 1978; MAJER 1992a; NAGY \& PINTÉR 1994, PURGER 1998a; SCHENK 1918; SZABÓ 1995.

31. Anser caerulescens (Linnaeus, 1758) Sarki lúd - SzAToru 1984.

32. Branta canadensis (Linnaeus, 1758) Kanadai lúd - FenYốsı 1999a.

33. Branta leucopsis (Bechstein, 1803) Apácalúd - FenYösı 1997; HADARICS 1997b, 1998a.

34. Branta bernicla (Linnaeus, 1758) - Örvös lúd - HaVRANEK 1996a; KEVE 1973.

35. Branta ruficollis (Pallas, 1769) Vörösnyakú lúd - KEVE 1973, 1978.

36. Tadorna tadorna (Linnaeus, 1758) . Bütykös ásólúd - BARTHOS 1951; HAVRANEK 1996a; NAGY \& PINTÉR 1994.

37. Anas penelope Linnaeus, 1758 - Fütyülö réce - FENYÖSI I 993a, 1996, 1997, 1999b, 2000; HaVraneK 1996b; Kasza \& Marián 2001; KÁRPÁTI 1979; KEVE 1973, 1975, 1978; NAGY \& PinTÉR 1994, PURGer 1998a.

38. Anas strepera Linnaeus, 1758 - Kendermagos réce - FENYÖSI 1993a, 1996, 1997, 1999b, 2000; GYULAI 1904; HAVRANEK 1996b; KASZA \& MARIÁN 2001; KeVE 1973, 1975, 1978; NAGY \& PINTÉR 1994; SCHENK 1918.
39. Anas crecca Linnaeus, 1758 - Csörgố réce - BANK 1998; FENYÖSI 1993a, 1995a, 1996, 1997, 1999b, 2000; FENYÓSI \& HORVÁTH 2000b; FÖlDVÁRY 1929; GYÖRGYPÁl 1978; HaVRANEK 1996b; HaVRaneK et. al. 1995a; KASZA \& MARIÁN 2001; KÁrPÁTI 1979; KeVE 1973, 1975, 1978; KÁRPÁTI 1977; MAJER 1992b; MARIÁN 1957, 1959; MARIÁN \& Puskás 1985; Purger 1998a; TeVely 1996.

40. Anas platyrhynchos Linnaeus, 1758 - Tökés réce - BANK 1998; BALI 1983; FENYÖSI 1993a, 1996, 1997, 1999b, 2000; FÖLDVÁRY 1929; KASZA \& MARIÁN 2001; KÁRPÁTI 1979, 1980; KeVE 1973, 1975, 1978; HAVRANEK 1996b; HAVRANEK et. al. 1995a; MAJER 1992a, 1992b; MARIÁN 1957, 1958b, 1959; MARIÁN \& PusKás 1985; Purger 1998a; TeVely 1996; TÖMÖSVÁRY et. al. 2000.

41. Anas acuta Linnaeus, 1758 - Nyílfarkú réce - BANK 1998; FENYÖSI 1996, 1997, 2000; KASZA \& MARIÁN 2001; KÁRPÁTI 1979; KeVE 1973, 1975, 1978; MAJER 1992b; MARIÁN 1957, 1959; NAGY \& PinTÉr 1994.

42. Anas querquedula Linnaeus, 1758 - Böjti réce - BANK 1998; FENYÖSI 1993a, 1996, 1997, 1999b, 2000; Havranek 1996b; HAVRANEK et. al. 1995a; KASZa \& MARIÁN 2001; KÁRPÁti 1979; KeVE 1973, 1975, 1978; MAJer 1992a, 1992b; MARIÁN 1957, 1959; MARIÁN \& PUSKÁS 1985; PURGER 1998a; TÖMÖSVÁRY et. al. 2000.

43. Anas clypeata Linnaeus, 1758 - Kanalas réce - BANK 1998; FENYÖSI 1993a, 1996, 1997, 1999b, 2000; HAVRANEK 1996b; KASZA \& MARÍ́N 200I; KEVE 1973, 1978; MAJER 1992a; Nagy \& Pintér 1994, Purger 1998a; SCHENK 1918.

44. Netta rufina (Pallas, 1773) - Üstökösréce - Hadarics 1998b; HaVRanek 1995, 1996b; HaVraneK et. al. 1995a; NAGY \& PinTÉr 1994.

45. Aythya ferina (Linnaeus, 1758) - Barátréce - BANK 1998; FENYÖSI 1996, 1997, 1999b, 2000; HavraneK 1995, 1996b; Havranek et. al. 1995a; KASZA \& MARIÁN 200l; KÁrPÁTI 1979; KeVE 1973, 1975, 1978, 1983; MAJER 1992a; PURGer 1998a; SCHENK 1918.

46. Aythya nyroca (Güldenstädt, 1770) - Cigányréce - BANK 1998; BANKOVICS 1985; FENYŐSI 1993a, 1996, 1997, 1999b, 2000; FÖldVÁRY 1929; HAVRANEK 1996b; HaVRANEK et. al. 1995a; KASZA \& MARIÁN 2001; KÁRPÁTI 1979, 1980; KEVE 1973, 1975, 1978; MAJER 1992a, 1992b; MARIÁN 1957, 1958b, 1959; MARLÁN \& PUSKÁS 1985; NAGY \& Pintér 
1994; SCHENK 1918; TEVELY 1996; TÖMÖSVÁRY et. al. 2000.

47. Aythya fuligula (Linnaeus, 1758) - Kontyos réce - BANK 1998; FenYósi 1996, 1997, 2000; HaVRANEK 1996b; HAVRANEK et. al. 1995a; KASZA \& MARIÁN 2001; KÁRPÁTI 1979; KEVE 1973, 1975, 1978, 1983; MAjER 1992a; MOLNÁR 1982c, 1983, 1984b, 1985, 1987b; NAGY \& Pintér 1994, Purger 1998a.

48. Aythya marila (Linnaeus, 1761) - Hegyi réce - BANK 1998; BANKOVICS 1985; MOLNÁR 1982c; FENYÓSI 1996, 1997; GYENEI \& SZABÓ 1995, 1996; HAVRANEK 1995, 1996b; HAVRANEK et. al. 1995a; MOLnÁR 1984b; NAGY \& PINTÉr 1994.

49. Somateria mollissima (Linnaeus, 1758) Pehelyréce - BanKovics 1985; FenYósi 1996, 1997; KEVE 1978, 1983; MOLNÁR 1984b; NAGY \& PINTÉR 1994.

50. Clangula hyemalis (Linnaeus, 1758) Jegesréce - FenYösi 1996, 1997; HAVRANeK 1995, 1996b; HAVRANEK et. al. 1995a; KEVE 1978; NAGy \& Pintér 1994; SCHENK 1918.

51. Melanitta nigra (Linnaeus, 1758) - Fekete réce-SChenk 1918; Hadarics 1998a.

52. Melanitta fusca (Linnaeus, 1758) - Füstös réce - BANK 1998; BANKOVICS 1985; FENYŐ́SI 1996, 1997; HADARICS 1996b, 1998a; HaVRANEK 1995, 1996b; HaVRANEK et. al. 1995a; KeVE 1978; MolnÁr 1985; NaGY \& PINTÉR 1994; SCHENK 1918.

53. Bucephala clangula (Linnaeus, 1758) Kerceréce - BANK 1998; BANKOVICS 1985; FENYŐSI 1996, 1997, 1999b, 2000; HAVRANEK 1995, 1996b; HAVRANEK et. al. 1995a; KÁRPÁTI 1979; KEVE 1973, 1975, 1978, 1983; PURGER 1998a.

54. Mergus albellus Linnaeus, 1758 - Kis bukó - BANK 1998; FeNYÖSI 1996, 1997, 2000; HAVRANEK 1996b; HAVRANEK et. al. 1995a; KÁrPÁtI 1979; KeVE 1973, 1975, 1978; MAJER 1992a; NAGY \& Pintér 1994.

55. "Nergus serrator Linnaeus, 1758- Örvös bukó - BANKOVICS 1985; HADARICS 1998a; Keve 1978; NAGy \& Pintér 1994; SChenk 1918.

56. Mergus merganser Linnaeus, 1758 - Nagy bukó - BANK 1998; BANKOVICS 1985; FENYÓSI 1996, 1997; HaVRANEK 1996b; HAVRANEK et. al. 1995a; KASZA \& MARIÁN 2001; KeVE 1973, 1978; M.O.K. 1895; NAGY \& PinTÉr 1994.

\section{ACCIPITRIFORMES - VÁGÓMADÁR-ALAKÚAK}

\section{Accipitridae - Vágómadárfélék}

57. Pernis apiporus (Linnaeus, 1758) - Darázsölyv - BANK 1998; FENYŐSı 1993a, 1993c,
1996; FILOTÁS 1996; GYÖRGYPÁL 1978; HOMONAY 1959a; KASZA \& MARIÁN 200I; KÁRPÁti 1979, 1980; Keve 1973, 1978; Majer 1992b; MARIÁN 1957, 1959; MARIÁN \& PuSKÁs 1985; NAGY \& PinTér 1994; NémeTH 1996; Purger 1998; SChenk 1918; Tevely 1996; VASVÁrI 1937.

58. Milvus migrans (Boddaert, 1783) - Barna kánya - BANK 1998; FENYŐSI 1993a, 1996, 2000; Filotás 1996; Kasza \& Marlán 2001; KÁrPÁti 1979; KeVE 1973, 1978; MAJER 1992a, 1992b; MARIÁN \& PUSKÁS 1985; NAGY \& Pintér 1994; Németh 1996; Purger 1998a; TilesCH 1986c.

59. Milıus milius (Linnaeus, 1758) - Vörös kánya - FenYösi 1996, 2000; NAGY \& PINTÉR 1994.

60. Haliaeetus albicilla (Linnaeus, 1758) Rétisas - BANK 1998; BREUER 1955a; FENYŐSI 1993a, 1993c, 1994c, 1996, 2000; FENYÖsI \& Stix 1998; Filotás 1996; Havranek 1995; KASZA \& MARIÁN 2001; KÁrPÁTI 1979, 1980 ; KeVe 1973, 1975, 1978; Majer 1992a, 1992b; Marián 1957, 1958a, 1959; MARIÁN \& PUSKÁs 1985; NAGY \& PINTÉr 1994; NÉMETH 1996; Purger 1998a; SÁra 1970a; SCHenk 1918; TeVElY 1996; TÖMÖSVÁRY 1982a; TÖMÖSVÁRY 1995; VASVÁR 1937.

61. Gyps fulvus (Hablizl, 1783) - Fakó keselyú - FöldVÁRY 1938.

62. Circaetus gallicus (J. F. Gmelin, 1788) Kigyászölyv - FENYŐSI 1993a, 1996, 2000; KÁrpÁti 1979, 1980; Keller 1937; KeVE 1978; NAGY \& PINTÉR 1994; NéMETH 1996; VASVÁRI 1937.

63. Circus aeruginosus (Linnaeus, 1758) Barna rétihéja - BANK 1998; FeNYÖSI 1993a, 1996, 2000; KASZA \& Marú́N 2001; KáRPÁTI 1979; KeVe 1973, 1975, 1978; MAjer 1992a, 1992b; MARIÁN 1957, 1958b, 1959; NAGY \& PINTÉR 1994; NÉMETH 1996.

64. Circus cyaneus (Linnaeus, 1766) - Kékes rétihéja - BANK 1998; FENYŐSI 1993a, 1996, 2000; KASZA \& MARIÁN 2001; KáRPÁTI 1979; Keve 1973, 1975, 1978; NAGY \& Pintér 1994; Németh 1996; Purger I998a.

65. Circus macrourus (S. G. Gmelin, 1771) Fakó rétihéja - KASZA \& MARIÁN 2001; KeVE 1978; NAGY \& PinTér 1994.

66. Circus pygargus (Linnaeus, 1758) Hamvas rétihéja - CHernel 1921; FenYÖSI 1993a, 1996, 2000; KASZA \& MARIÁN 2001; KeVe 1973, 1978; Majer 1992b; Marián 1957, 1959; NAGY \& PINTÉR 1994.

67. Accipiter gentilis (Linnaeus, 1758) - Héja - BANK 1998; Fallon-Kund 1937; FENYÖSI 
1993a, 1993c, 1996, 2000; FENYÖSI \& STIX 1996; KASZA \& MARIÁN 2001; KÁRPÁTI 1979. KeVE 1973, 1978; Majer 1992a, 1992b; MARLÁN 1957, 1959; MARIÁN \& PUSKás 1985; NAGy \& Pintér 1994; Németh 1996; Purger 1998a; TeVEly 1996.

68. Accipiter nisus (Linnaeus, 1758) - Karvaly - BANK 1998; Fallon-Kund 1937; FENYÖSI 1993a, 1993c, 1996, 2000; KASZA \& MARLÁN 2001; KÁRPÁTI 1979; KEVE 1973, 1975, 1978; MAJER 1992a; MARIÁN \& PuSKás 1985; NAGY \& Pintér 1994; Németh 1996; Purcer 1998a; TeVELY 1996.

69. Buteo buteo (Linnaeus, 1758) - Egerészölyv - BANK 1998; BARIOS 1906b, 1908 ; Fallon-Kund 1937; FENYÖSI 1993a, 1993b, 1993c, 1996, 2000; FENYÖSI \& STIX 1998; KASZA \& MarIÁN 2001; KeVE 1973, 1975, 1978; MAJER 1992a, 1992b; MARIÁN 1957, 1959; MARIÁN \& PUSKÁS 1985; NAGY \& PINTÉR 1994; NÉmElH 1996; PURGer 1998a; Tevely 1996; Tilesch 1989.

70. Buteo lagopus (Pontoppidan, 1763) - Gatyás ölyv - BANK 1998; FENYŐ́sı 1993a, 2000; KaSza \& MARIÁN 2001; KúrPÁTI 1979; KeVE 1973, 1978; MAJER 1992b; MARIÁN 1957, 1959; Marián \& Puskás 1985; NAGY \& Pintér 1994; NÉMETH 1996

71. Aquila pomarina C. L. Brehm, 1831 Békászó sas - FeNYösı 1993a, 1996, 2000; HoRVÁth 2001; KALOTÁS 1986; KASZA \& MARIÁN 2001; Keve 1978; NAGY \& PINTÉR 1994; NÉMETH 1996.

72. Aquila heliaca Savigny, 1809 - Parlagi sas - FenYósi 1996; NAGY \& PINTÉr 1994.

73. Hieraaetus pennatus (J. F. Gmelin, I788) - Törpesas - NAGY \& PINTÉr 1994; NÉMETH 1996.

\section{Pandionidae - Halászsasfélék}

74. Pandion haliaetus (Linnaeus, 1758) - Halászsas - BANK 1998; FENYÖSI 1993a, 1996, 2000; HADARICS 1996d, 1997b, 1997d; KÁRPÁtI 1979; KEVE 1973, 1978; KIRÁLY 1957; MARIÁN \& PuSKÁS 1985; MOLNÁR 1982b, 1982c; NAGY \& PINTÉr 1994; NÉMETH 1996; SCHENK 1918; TÖMÖSVÁRY 1982a; VASVÁRI 1928.

\section{FALCONIFORMES - SÓLYOMALAKÚAK}

\section{Falconidae - Sólyomfélék}

75. Falco naumanni Fleischer, 1818 - Fehérkarmú vércse - BARTOS 1906b; KEVE 1978; SCHENK 1918.

76. Falco tinnunculus Linnaeus, 1758 - Vörös vércse - BANK 1998; Fallon-Kund 1937; FENYŌSI 1993a, 1996, 2000; KASZA \& MARIÁN
2001; KÁRPÁTI 1979; KEVE 1973, 1975, 1978; Majer 1992a; Marián \& PUSKás 1985; NAGY \& Pin'ér 1994; Németh 1996; Purger 1998a.

77. Falco pespertinus Linnaeus, 1766 - Kék vércse - FENYÓSI I996; KEVE 1973, 1978; NAGY \& PinTÉR 1994; NÉMETH 1996; SCHENK 1918.

78. Falco columbarius Linnaeus, 1758 - Kis sólyom - BANK 1998; FENYÖSI 1993a, 1996, 2000; HADARICS 1997a, 1997b, 1998a, 1998d; KASZA \& MARIÁN 2001; Keve 1973, 1975, 1978; MOLNÁR 1982h, 1984b, 1985, 1986; NAGY \& P'INTÉr 1994; Németh 1996; Purger $1998 \mathrm{a}$.

79. Falco subbuteo Linnaeus, 1758 - Kabasólyom - BANK 1998; Fallon-Kund 1937; FENYÖSI 1993a, 1996, 2000; Filotás 1996; KASZA \& Marlán 2001; Kárpáti 1979; KeVE 1973, 1975, 1978; MAJER 1992a; MARIÁN \& PUSKÁS 1985; NAGY \& PINTÉr 1994; NÉmETH 1996; Purger 1998a; Tevely 1996.

80. Falco cherrug J. E. Gray, 1834 - Kerecsensólyom - KeVE 1978; NAGY \& PiNTÉr 1994; NÉMETH 1996.

81. Falco peregrinus Tunstall, 1771 - Vándorsólyom - FENYÓSI 1996; HADARICS 1997c; KEVE 1978; MARIÁN 1958a; MOLNÁR 1982c, 1984b; NAGy \& Pintér 1994; NÉmETH 1996.

\section{GALliformes - TYúKALAKÚAK}

\section{Tetraonidae - Fajdfélék}

82. Bonasa bonasia (Linnaeus, 1758) - Császármadár - FENYŐSI I 993a, 2000; MARIÁN \& PUSKás 1985; NAGY \& PinTÉr 1994.

\section{Phasianidae - Fácánfélék}

83. Perdix perdix (Linnaeus, 1758) - Fogoly BANK I998; BARTOS 1906b; FENYÓSI 2000; KÁRPÁTI 1979; KeVE 1973, 1978; PURGER 1998a.

84. Coturnix coturnix (Linnaeus, 1758) - Fürj - BANK I998; FENYÖSI 1996, 2000; HAVRANEK 1995; KASZA \& MARIÁN 2001; KÁRPÁTI 1979; KeVE 1973, 1978; NAGY \& PINTÉr 1994, Purger 1998a; Tevely 1996; Ujváry 1917.

85. Phasianus colchicus Linnaeus, 1758 - Fácán - Bank 1998; Bartos 1906b; Chernel 1921 ; FENYÔSI 1993a, 1996, 2000; KASZA \& MARLÁN 2001; KÁRPÁTI 1979; KEVE 1973, 1975, 1978; MAJER 1992a, 1992b; MARLÁN 1957, 1959; MARLÁN \& PUSKÁS 1985; PURGER 1998a; TeVEly 1996.

\section{GRUiformes - DarualakúaK}

\section{Rallidae - Guvatfélélk}

86. Rallus aquaticus Linnaeus, 1758 - Guvat - FENYÖSI 1993a, 1996, 1999b, 2000; HaVraneK 1996b; Kasza \& Marián 2001; 
KÁRPÁTI 1979, 1980; KEVE 1973, 1975, 1978 MAJER 1992a, 1992b; MARLÁN \& PUSKÁS 1985; Nagy \& Pintér 1994, Purger 1998a; Tevely 1996; TÖMÖSVÁRY et. al. 2000.

87. Porzana porzana (Linnaeus, 1766) Pettyes vízicsibe - FENYŐSI 1996, 2000; KASZA \& Marián 2001; KáRPÁTI 1979; KeVE 1973, 1975, 1978; MAJER 1992b; MARIÁN 1957, 1959; Nagy \& Pintér 1994, Purger 1998; Tevely 1996.

88. Porzana parra (Scopoli, 1769) - Kis vízicsibe - FEnYösI 1999b, 2000; HavraneK 1996b; KeVE 1973, 1975, 1978; NAGY \& PINTÉr 1994; SCHENK 1918; TÖMÖSVÁRY et. al. 2000.

89. Porzana pusilla (Pallas, 1776) - Törpevízicsibe - TÖMÖSVÁRY et. al. 2000.

90. Crex crex (Linnaeus, 1758) - Haris FenYósi 1996; Keve 1973, 1975, 1978; NAGY \& Pintér 1994, Purger 1998a; Szabó 1996d.

91. Gallinula chloropus (Linnaeus, 1758) Vízityúk - BANK 1998; FENYÓSI 1993a, 1996, 1999b, 2000; FöldVÁrY 1929; HAVRANEK 1996b; KASZA \& MARIÁN 2001; KÁRPÁTI 1979, 1980; KeVE 1973, 1975, MAJER 1992a, 1992b; MARIÁN 1957, I959; MARIÁN \& PUSKÁs I985; Nagy \& Pintér 1994, Purger 1998a; Tevely 1996; TÖMÖSVÁRY et. al. 2000.

92. Fulica atra Linnaeus, 1758 - Szárcsa AGÁRDI 1935; BALI 1983; BANK 1998; FENYÖSI 1993a, 1996, 1997, 1999b, 2000; FÖLDVÁRY 1929; HavraneK 1996b; HaVRANEK et. al. 1995a; KASZA \& MARIÁN 2001; KÁRPÁTI 1979; KeVE 1973, 1975, 1978, 1982; MAJER 1992a, 1992b; MARIÁN 1957, 1958b, 1959; MARIÁN \& Puskás 1985; Purger 1998a; Tevely 1996; TÖMÖSVÁRY et. al. 2000.

\section{Gruidae - Darufélék}

93 Grus grus (Linnaeus, I758) - Daru BARTHOS 1947; B.B. 1924; BERZSENYI 1918; Fallon-Kund 1937; FENYŐSI 1993a, 1996, 2000; Havranek 1995, 1996b; Havranek et. al. 1995a; KÁRPÁTI 1979; Keller 1937; KeVE 1973, 1978; M.O.K. 1895; NAGY \& PINTÉR 1994; SCHENK 1918.

\section{Otididae - Túzokfélék}

94. Tetrax tetrax (Linnaeus, 1758) - Reznek - Keller 1936; Keve 1978; Maruán 1958a; SZAlAY 1934.

95. Otis tarda Linnaeus, 1758 - Túzok CSERY 1929; Fallon-Kund 1937; KASZA 1983a; KeVE 1978; MARIÁN 1958a; NAGY \& PINTÉr 1994; VASVÁRI 1942.
Charadrifformes - LiLealakúaK

Haematopodidae - Csigaforgató-félék

96. Haematopus ostralegus Linnaeus, 1758 -

Csigaforgató - Keve 1978; SCHENK 1918.

\section{Recurvirostridae - Gulipánfélék}

97. Himantopus himantopus (Linnaeus, 1758) - Gólyatöcs - FenYÖSI 1996; HAVRANEK 1996b; KeVE 1973, 1978; NAGY \& PinTÉr 1994; SCHENK 1918; SZABÓ 1996a.

98. Recurvirostra avosetta Linnaeus, 1758 Gulipán - Breuer 1955b; Havranek 1995; KASZA \& MARIÁn 2001; NAGY \& Pintér 1994; SZABÓ 1996a.

\section{Burhinidae - Ugartyúkfélék}

99. Burhinus oedicnemus (Linnaeus, 1758) Ugartyúk - CHERNel 1921, 1922; FENXÖSI 2000; KárpátI 1979, 1980; Keve 1978; NAGY \& Pintér 1994; SzÉCHeNYI 1942.

\section{Glareolidae - Székicsérfélék}

100. Glareola pratincola (Linnaeus, 1766) Székicsér - Gyulai 1904; Keve 1973, 1978; SCHENK 1918; SzABÓ 1996a.

\section{Charadriidae - Lilefélék}

101. Charadrius dubius Scopoli, 1786 - Kis lile - BANK 1998; BÉCSY et. al. 1995; FENYÖSI 1993a, 1993d, 1996, 1998b, 2000; GYULAI 1904; Havranek 1996b; Keve 1973, 1978; Majer 1992a; Nagy \& Pintér 1994, Purger 1998a; SÁra 1970a; SzABÓ 1996a.

102. Charadrius hiaticula Linnaeus, 1758 Parti lile - GyUlaI 1904; Hadarics 1996d; Keve 1973, 1978; Nagy \& Pintér 1994; SCHENK 1918; SZABÓ 1996a.

103. Charadrius alexandrinus Linnaeus, 1758 - Széki lile - Gyulai 1904; Keve 1978; SCHENK 1918.

104. Pluvialis apricaria (Linnaeus, 1758) Aranylile - FenYösi 1996; GYUlaI 1904, KeVE 1973, 1978; NAGY \& PINTÉR 1994; SCHENK 1918; Szabó 1996a.

105. Pluvialis squatarola (Linnaeus, 1758) Ezüstlile - FeNYŐSI 1996; GYULAI 1904, KeVE 1973, 1978; MOLNÁR 1982h, 1984b, 1985, 1987a, 1988b; NAGY \& PINTÉR 1994; SCHENK 1918; SzAвó 1996a.

106. Vanellus vanellus (Linnaeus, 1758) - Bíbic - AGÁrdI 1935; BANK 1998; Fallon-Kund 1948; FenYÖSI 1993a, 1996, 2000; HAVRANEK 1996b; KASZA \& MARIÁN 2001; KÁRPÁTI 1979; KeVE 1973, 1975, 1978; Majer 1992a, 1992b; MARIÁN 1957, 1959; MARIÁN \& PUSKÁS 1985; 
Nagy \& Pintér 1994, Purger 1998a; Szabó 1996a; UJVÁRY 1917.

\section{Scolopacidae - Szalonkafélék}

107. Calidris canutus (Linnaeus, 1758) Sarki partfutó - KeVE 1973, 1978; SCHENK 1918; SzABó 1996a.

108. Calidris alba (Pallas, 1764) - Fenyérfutó - Grulai 1904; Keve 1973, 1978; SChenK 1918; SzABó 1996a.

109. Calidris minuta (Leisler, 1812) - Apró partfutó - GYULAI 1904, KeVE 1973, 1978; NAGY \& PinTÉr I994; SZABÓ 1996a.

110. Calidris temminckii (Leisler, 1812) Temminck-partfutó - KEVE 1973, 1978; NAGY \& Pintér 1994; Szabó 1996a.

111. Calidris ferruginea (Pontoppidan, 1763) - Sarlós partfutó - FENYŐSI 1996; HaVRanek 1996b; KeVe 1978; Nagy \& Pintér 1994; SCHENK 1918; SZABÓ 1996a.

112. Calidris alpina (Linnaeus, 1758) - Havasi partfutó - FENYÓSI 1996; GYULAI 1904; HAVRANEK 1996b; Keve 1973, 1978; NAGY \& Pintér 1994; SCHEnk 1918; Szabó 1996a.

113. Limicola falcinellus (Pontoppidan, 1763) - Sárjáró - KeVE 1978; SzABó 1996a.

114. Philomachus pugnax (Linnaeus, 1758) Pajzsoscankó - FENYÖSI 1996; HAVRANEK 1996b; KASZA \& MARIÁN 2001; KeVE 1973, 1975, 1978; NAGY \& PINTÉR 1994; SZABÓ 1996a.

115. Lymnocryptes minimus (Brünnich, 1764) - Kis sárszalonka - FenYösı 1996; Keve 1978; MOLNÁR 1985, 1987b; SZABÓ 1996a.

1 16. Gallinago gallinago (Linnaeus, 1758) Sárszalonka - BANK 1998; FENYŐSI 1993a, 1996, 2000; HaVRANEK 1996b; Kasza \& Marián 2001; KárpÁti 1979; Keve 1973, 1975, 1978; Majer 1992a; NAGY \& Pintér 1994; Szabó 1996a; Tevely 1996.

117. Gallinago media (Latham, 1787) Nagy sárszalonka - MOLNÁr 1982b; KEVE 1973, 1978; SzАBÓ 1996а.

118. Scolopax rusticola Linnaeus, 1758 - Erdei szalonka - Fallon-Kund 1948; FENYŐSI 1993a, 1996, 2000; FENYÖSI \& STIX 1993; Hadarics 1997a, 1997b, 1999; Havranek 1996b; KASZA \& MARIÁN 200l; KÁRPÁTI 1979; Keve 1978; Majer 1992b; MariÁn 1957, 1958b, 1959; MARIÁN \& PUSKÁS 1985; PURGER 1998a; SZABÓ 1996a; UJVÁRY 1917.

119. Limosa limosa (Linnaeus, 1758) - Nagy goda - FENYÖSI 1996; HAVRANEK 1996b; KASZA \& Marián 2001; KeVE 1973, 1978; NAGY \& PINTÉr 1994; Szabó 1996a.

120. Limosa lapponica (Linnaeus, 1758) -
Kis goda - Keve 1978; Nagy \& Pintér 1994; SCHENK 1918.

121. Numenius phaeopus (Linnaeus, 1758) Kis póling - KeVE 1978; MOLNÁr 1984b; SCHENK 1918.

122. Numenius arquata (Linnaeus, 1758) Nagy póling - BANK 1998; CHERnel 1921; FENYöSI 1996; HaVRANEK 1996b; Keve 1973, 1975, 1978; NAGY \& Pintér 1994; SzABó 1996 a.

123. Tringa erythropus (Pallas, 1764) - Füstös cankó - BANK 1998; FENYÓSI 1993a, 1996, 2000; HAVRANEK 1996b; KASZA \& MARIÁN 2001; Keve 1973, 1975, 1978; Nagy \& Pintér 1994; SCHENK 1918; SZABÓ 1996a.

124. Tringa totanus (Linnaeus, 1758) Piroslábú cankó - AGÁRDI 1935; FENYÓSI 1996, 2000; HaVRaneK 1996b; Kasza \& MarLán 2001; KeVe 1973, 1975, 1978; MajER 1992a; Marián \& Puskás 1985; MolnÁr 1982g; NAGY \& Pintér 1994, Purger 1998a; SCHENK 1918; SzABó 1996a.

125. Tringa stagnatilis (Bechstein, I803) Tavi cankó - HaVraneK 1996b; KeVE 1978; MolnÁr 1985, 1987b; Nagy \& Pintér 1994; SCHenk 1918; SzABó 1996a.

126. Tringa nebularia (Gunnerus, 1767) Szürke cankó - BANK 1998; FAUniszTiKa; FENYŐSI 1993a, 1996, 2000; HAVRANEK 1996b; Kasza \& Marián 2001; Keve 1973, I975, 1978; MOLNÁR 1982c, 1983; NAGY \& PinTér 1994; SChenk 1918; Szabó 1996a; Tevely 1996.

127. Tringa ochropus Linnaeus, 1758 - Erdei cankó - BANK 1998; FENYÖSI 1993a, 1996, 2000; HaVRANEK 1996b; KAsza \& Marián 2001; Keve 1973, 1978; Majer 1992a; MOLNÁR 1982b, 1982h; NAGY \& PinTÉr 1994, Purger 1998a; SÁra 1970a; Szabó 1996a; TEVELY 1996.

128. Tringa glareola Linnaeus, 1758 - Réti cankó - FENYÓSI 1993a, 1996, 2000; HAVRANEK 1996b; KeVE 1973, 1975, 1978; NAGY \& PinTér 1994; SChenk 1918; Szabó 1996a; TeVely 1996.

129. Actitis hypoleucos (Linnaeus, 1758) Billegetőcankó - BANK1989a, 1998; BéCSY et. al. 1995; FenYósi 1993a, 1996, 2000; GyULAI 1904; HAVRANEK 1996b; KASZA \& MARLÁN 2001; KÁRP̈́tI. 1979; KeVE 1973, 1975, 1978 ; Majer 1992a; Nagi \&\& Pintér 1994, Purger 1998a; Sżabó 1996a:'Tevely 1996.

130. Akenaria interpres (Linnaeus, 1758) Kőforgató - Hadarics 1996d; Keve 1973, 1978; SCHENK' 1918; SZAB́ó 1996a. 
131. Phalaropus lobatus (Linnaeus, 1758) Vékonycsórüi víztaposó - KEVE 1978; SCHENK 1918; SZABÓ 1996a.

\section{Stercorariidae - Halfarkasfélék}

132. Stercorarius pomarinus (Temminck, 1815) - Szélesfarkú halfarkas - Grulai 1904; KEVE 1974, 1978; SCHENK 19I8.

133. Stercorarius parasiticus (Linnaeus, 1758) - Ékfarkú halfarkas - KEVE 1974, 1978; MOLnÁr 1992.

\section{Laridae - Sirályfélék}

134. Larus ichthyaetus Pallas, 1773 - Halászsirály - HAVRANEK 1996b.

135. Larus melanocephalus Temminck, 1820 - Szerecsensirály - GyUlaI 1904; KeVE 1974, 1978; SCHENK I918.

136. Larus minutus Pallas, 1776 - Kis sirály - Bank 1998; Gyulai 1904; Havranek 1996b; HavraneK et. al. 1995a; Keve 1973, 1974, 1978; MOLNÁR 1982c, I982h, 1983, 1984b, 1985, 1987b, 1988a; M.O.K. 1895; NAGY \& PinTÉr 1994; SCHENK 1918.

137. Larus ridibundus Linnaeus, 1766. Dankasirály - AGÁRDI 1935, 1968; BALI 1983; BANK 1998; CHERNEL 1921; FENYÖSI 1993a, 1996, 1997, 2000; HAVRANEK 1996b; HAVRANEK et. al. 1995a, 1995b; KASZA \& MARIÁN 2001; KÁRPÁTI 1979; KeVE 1973, 1974, 1975, 1978; MAJER 1992a, 1992b; Marián 1957, 1958b, 1959; NAGY \& PinTÉr 1994; PURGER 1998a; SCHENK 1918; TEVELY 1996.

138. Larus canus Linnaeus, 1758 - Viharsirály - BANK 1998; FENYÖSI 1996, 1997; HavraneK 1996b; Havranek et. al. 1995a; KeVe 1973, 1974, 1975, 1978; NAGY \& PINTÉr 1994; SCHENK 1918.

139. Larus fuscus Linnaeus, 1758 - Heringsirály - BANKOVICS 1985; GyULAI 1904, HaVRaneK 1996b; HaVRaneK et. al. 1995a; KeVE 1973, 1974, 1978; MOLNÁR 1982c, 1985, 1987b; NAGY \& PinTÉr 1994; SCHENK 1918.

140. Larus argentatus Pontoppidan, 1763. Ezüstsirály - BANK 1998; GYULAI 1904, Havranek et. al. 1995a; Keve 1973, 1974, 1975, 1978; MAJER 1992a; PURGER 1998a.

141. Larus cachinnans Pallas, 1811 - Sárgalábú sirály - FENYŐ́s 1997; HAVRANEK 1996b; KASZA \& MARIÁN 2001; SCHENK 1918.

142. Lanus glaucoides B. Meyer, 1822 - Sarki sirály - KeVE 1974, 1978.

143. Larus marinus Linnaeus, 1758 - Dolmányos sirály - MOLNÁR 1985; NAGY \& PINTÉR 1994.
144. Rissa tridactyla (Linnaeus, 1758) Csüllö - MOLNÁr 1982c, 1982h, 1987b; KEVE 1973, 1974, 1978; MOLNÁR 1982f.

\section{Sternidae - Csérfélék}

145. Gelochelidon nilotica (J. F. Gmelin, 1789) - Kacagócsér - KADA 1951; KEVE 1973, 1974, 1978; Magyar 1997; SCHENK 1918.

146. Stema caspia Pallas, 1770 - Lócsér HavraneK 1996b; Keve 1973, 1974, 1975, 1978; MolnÁR 1983, I984b; NAGY \& Pintér 1994.

147. Stema sandivicensis Latham, 1787 Kenti csér - HavraneK 1995, 1996b; HAVRANEK et. al. 1995a, 1995b; LÁszló 1996.

148. Sterna hirundo Linnaeus, 1758 - Küszvágó csér - AGÁRDI 1935; BALl 1983; BANK 1998; BÉCSY et. al. 1995; FENYŐ́SI 1996 , 1998b, 2000; GyUlAI 1904; HAVRANEK 1996b; KASZA \& MarIÁN 2001; Kárpáti 1979; KeVE 1973, 1974, 1975, 1978; MAJER 1992b; Marián 1957; NAgy \& Pintér 1994, Purger $1998 \mathrm{a}$.

149. Sterna albifrons Pallas, 1764 - Kis csér - BéCSY et. al. 1995; FeNYÖSI 1996, 1998b; GYULAI 1904; HADARICS 1996c, 1997c, 1998c; KEVE 1974, 1978; MOLNÁr 1984b, 1987b; NAGY \& PinTér 1994, Purger 1998a; SCHENK 1918.

150. Chlidonias hybridus (Pallas, 1811) Fattyúszerkő - HAVRANEK 1996b; KASZA \& Maruán 2001; KeVE 1973, 1974, 1978.

151. Chlidonias niger (Linnaeus, 1758) Kormos szerkô - AGÁrdI 1935; BANK 1998; FENYÔSI 1993a, 1996, 2000; HAVRANEK 1996b; Kasza \& Marián 2001; Kárpáti 1979; KeVE 1973, 1974, 1975, 1978; NAGY \& PINTÉR 1994, PURGER 1998a; SCHENK 1918.

152. Chlidonias leucopterus (Temminck, 1815) - Fehérszárnyú szerkó - FENYôsı 1996; KASZA \& MaRIÁN 2001; Keve 1973, 1974, 1978.

\section{COLUMBIFORMES - GALAMBALAKÚAK}

\section{Columbidae - Galambfélék}

153. Columba oenas Linnaeus, 1758 - Kék galamb -BANK 1998; FENYÔSI 2000; KASZA \& MARIÁN 2001; KúRPÁTt 1979; KeVE 1975, 1978; MAJER 1992a, 1992b; MARLÁN 1957, 1959; Nagy \& Pintér 1994; Purger 1998a; SZÉCHENYI 1942; UjVÁRY 1917; VASVÁRI 1937.

154. Columba palumbus Linnaeus, 1758 Örvös galamb - BANK 1998; Fallon-Kund 1948; FENYÓSI 1993a, 1996, 2000; KASZA \& MARIÁN 2001; KÁRPÁtI 1979; KeVE 1973, 1975, 1978; MAJER 1992a, 1992b; MARIÁN 1957, 1959; 
Marián \& Puskás 1985; Mihalicz 1996; Purger 1998a; Tevely 1996; Ujváry 1917.

155. Streptopelia decaocto (E. Frivaldszky, 1838) - Balkáni gerle - BALI 1983; BANK 1998; FENYỐSı 1993a, 1996, 2000; GRESCHIK 1929; KASZA \& MARIÁN 2001; KúRPÁti 1979; KeVE 1973, 1975, 1978; MAJER 1992a; MARIÁN \& Puskás 1985; Purger 1998a; Tevely 1996.

156. Streptopelia turtur (Linnaeus, 1758) Vadgerle - BALI 1983; BANK 1998; FENYŐSI 1993a, 1996, 2000; KASZA \& MARIÁN 2001; KÁrpáti 1979; Keve 1973, 1975, 1978; MAJER 1992a, 1992b; MARIÁN 1957, 1959; MARIÁN \& Puskás 1985; NAGY \& Pintér 1994; Purger 1998a; TeVely 1996.

\section{Cuculiformes - KaKuKKalakúaK}

\section{Cuculidae - Kakukkfélék}

157. Cuculus canorus Linnaeus, 1758 - Kakukk - BANK 1998; BARTOS 1906d; FENYÓSı 1993a, 1996, 2000; HOMONAY 1959b; KASZA \& MARLÁN 2001; KÁRPÁTI 1979; KEVE 1973, 1975; Majer 1992b; MARLÁN 1957, 1958b, 1959; Marián \& Puskás 1985; NAGY \& Pintér 1994; Purger I998a; Ujváry 1917.

\section{STRIGIFORMES - BAGOLYALAKÚAK}

\section{Tytonidae - Gyöngybagolyfélék}

158. Tyto alba (Scopoli, 1769) - Gyöngybagoly - BANK 1998; FENYÓSI 1994d, 1996, 2000; FENYÔSI et. al. 1995, 1998; KALOTÁs 1987; Kalotás \& Pintér 1986; Keve 1978; NaGy \& PINTÉR 1994, PURGER 1996, 1997, 1998a, 1998b.

\section{Strigidae - Bagolyfélék}

159. Otus scops (Linnaeus, 1758). Füleskuvik - KEvE 1978; NAGY \& PINTÉr 1994.

160. Nyctea scandiaca (Linnaeus, 1758) Hóbagoly - NAGY \& PINTÉR 1994.

161. Athene noctua (Scopoli, 1769) - Kuvik - FenyốsI 2000; Filotís 1996; Kasza \& Marián 2001; Keve 1973, 1978; MajER 1992a, 1992b; MARLÁN 1957, 1959; MARIÁN \& Puskás 1985; Nagy \& Pintér 1994; Purger 1998a.

162. Strix aluco Linnaeus, 1758 - Macskabagoly - BANK 1998; BARTOS 1906b; FENYÖSI 1993a, 1996, 2000; Filotás 1996; Kalotás 1989; KASZA \& MARIÁN 200I; KÁRPÁTI 1979; KEVE 1978; MAJER 1992a, 1992b; MARLÁN 1957, 1959; MARIÁN \& PuSKás 1985; NAGY \& Pintér 1994; Purger 1998a; Tevely 1996.

163. Asio otus (Linnaeus, 1758) - Erdei fülesbagoly - BANK 1998; FENYÖSI 1993a, 1996, 2000; Filotás 1996; Kasza \& Marián 2001; KárPÁt 1979; KeVE 1973, 1978; MAJER 1992a; MARIÁN \& PuSKÁS I985; MOLNÁR
1983; Nagy \& Pintér 1994; Purger 1998a; SÁrA 1970a.

164. Asio flammeus (Pontoppidan, 1763) Réti fülesbagoly - BANK 1998; BARTOS 1906e; FENYŐSI I996; KEVE 1978; MAJER 1992b; Molnár 1982h; NAGy \& Pintér 1994; SCHENK 1918.

\section{CAPRIMULGIFORMES - LAPPANTYÚALAKÚAK}

\section{Caprimulgidae - Lappantyúfélék}

165. Caprimulgus europaeus Linnaeus, 1758 - Lappantyú - Bartos 1906b; FenYôsi 1993a, 2000; KASZA \& MARLÁn 2001; KÁRPÁtT 1979, 1980; KeVE 1978; MAJER 1992b; MARIÁN 1957, 1959; Marián \& PuSKás 1985; NAGY \& PINTÉr 1994.

\section{APODIFORMES - SARLÓSFECSKEALAKÚAK}

\section{Apodidae - Sarlósfecskefélék}

166. Apus apus (Linnaeus, 1758) - Sarlósfecske - BANK 1998; FENYÓSI 1993a, 1996, 2000; KASZA \& MARIÁN 2001; KEVE 1973, 1975, 1978; MarláN \& Puskás 1985; NAGY \& Pintér 1994; Purger 1998a; TeVely 1996.

\section{CORACIIFORMES - SZALAKÓTAALAKÚAK}

\section{Alcedinidae - Jégmadárfélék}

167. Alcedo atthis (Linnaeus, 1758) - Jégmadár - BANK 1998; FENYÓSI 1993a, 1996, 2000; HAVRANEK et. al. 1995a; KASZA \& MARIÁN 2001; KÁRPÁTI 1979; KEVE 1973, 1975, 1978; MAjer 1992a; MARIÁN \& PuSKás I985; NAGY \& Pintér 1994; Purger 1998a; Sára I970a; TEVELY I 996; VINCZE 1996.

\section{Meropidae - Gyurgyalagfélék}

168. Merops apiaster Linnaeus, 1758 - Gyurgyalag - BANK 1998; FENYÖSI 1993a, 1996, 2000; FILOTÁs 1996; KASZA \& MARIÁN 2001; Keve 1973, 1978; Marián 1958a; Marián \& PUSKÁS 1985; NAGY \& PINTÉr 1994; NOVOTNY 1996; Purger 1998a; SChenk 1918; Tevely 1996.

\section{Coraciidae - Szalakótafélék}

169. Coracias garrulus Linnaeus, 1758 - Szalakóta - BARTOS 1906b, 1906c, 1906d; FENYỐSI, 2000; FILOTÁS 1996; KASZA \& Marlán 2001; Kárpáti 1979; Keve 1973, 1975, 1978; MAJER 1992a, 1992b; MARIÁN 1957; Marián \& Puskás 1985; NAGY \& PinTÉr 1994.

\section{Upupidae - Bankafélék}

170. Upupa epops Linnaeus, 1758 . Búbosbanka - BALI 1983; BANK 1998; FENYÖSI 1993a, 1996, 2000; FILOTÁs 1996; KASZA \& 
MARIÁN 2001; KÁrpÁtI 1979; KeVE 1973, 1978; Majer 1992a, 1992b; Marián \& Puskás 1985; NAGY \& Pintér 1994; Novotny 1996; Purger 1998a; UjVÁRY 1917.

\section{PiCIFORMES - HARKÁLYALAKÚAK}

\section{Picidae - Harkályfélék}

171. Jynx torquilla Linnaeus, 1758 - Nyaktekercs -BANK 1998; FENYŐSI 1993a, 1996, 2000; Kasza \& Marián 2001; Kárpáti 1979; Keve 1973, 1978; MAJER 1992a, 1992b; MARJÁN 1957; Marián \& Puskás 1985; Nagy \& Pintér 1994; Purger 1998a.

172. Picus canus J. F. Gmelin, 1788 - Hamvas külló - BANK 1998; FENYÖSI 1993a, 1995b, 1996, 2000; KASZA \& Marián 2001; KÁRPÁTI 1979; KevE 1973, 1978; MAJER 1992a; MARIÁN \& PUSKÁS 1985; MOLNÁR 1982h, 1985, 1988b; NAGY \& Pintér 1994; Purger 1998a; TeVELY 1996.

173. Picus piridis Linnaeus, 1758 - Zöld külló - Bal 1983; BAnK 1984, 1998; FenYösI 1993a, 1996, 2000; KASZA \& MARIÁN 2001; KÁRpÁtI 1979; KeVE 1973, 1975, 1978; MAJER 1992a, 1992b; MARIÁN 1957, 1959; MarIáN \& Puskás 1985; Nagy \& Pintér 1994; PuRger 1998a; Tevely 1996.

174. Dryocopus martius (Linnaeus, 1758) Fekete harkály - BANK 1998; FENYÖSI 19992, 1993a, 1996, 2000; KASZA \& MARIÁN 200I; KÁrpáti 1979, 1980; Keve 1978; Majer 1992a, 1992b; MARIÁN 1957, 1958b, 1959; Marián \& Puskás 1985; NaGY \& Pintér 1994; Purger 1998a; SÁra 1970a; SzéchenyI 1942; TEVELy I996; TILESCH 1986c; VASVÁRI 1937; ZERGÉNYI 1934.

175. Dendrocopos major (Linnaeus, 1758) Nagy fakopáncs - BALI 1983; BANK I998; FENYŐSI 1993a, 1996, 2000; KASZA \& MARIÁN 2001; KÁrPÁtI 1979; KeVE 1975, 1978; MAJER 1992a, 1992b; MARLÁN 1957, 1958b, 1959; MARiÁn \& Puskás 1985; NAGY \& Pintér 1994, Purger 1998a; TeVely 1996...

176. Dendrocopos syriacus (Hemprich \& Ehrenberg, 1833) - Balkáni fakopáncs- BANK 1998; FENYÖSI 1996; KASZA \& MARIÁN 2001; Keve 1954, 1973, 1975, 1978; NAGy \& Pintér 1994, Purger 1998a; TeVEel 1996.

177. Dendrocopos medius (Linnaeus, 1758) Közép fakopáncs - BANK 1998; FENYŐSI 1993a, 1996, 2000; Kasza \& Marián 200I; Kárpáti 1979; Keve 1978; Marián \& Puskás 1985; Nagy \& Pintér 1994, Purger 1998a; Tevely 1996.

178. Dendrocopos leucotos (Bechstein, 1803) - Fehérhátú fakopáncs - NAGY \& PINTÉR 1994.
179. Dendrocopos minor (Linnaeus, 1758) Kis fakopáncs - BANK 1998; FENYŐSI 1993a, 1996, 2000; KASZA \& MARIÁN 2001; KÁRPÁTI 1979; Keve 1978; Majer 1992a; Marián \& PUSKKÁS 1985; NAGiY \& Pintér 1994, Purger 1998a; TeVely 1996.

\section{Passeriformes - VerébalakúaK}

\section{Alaudidae - Pacsirtafélék}

180. Calandrella brachydactyla (Leisler, 1814) - Szikipacsirta - Keve 1973.

181. Galerida cristata (Linnaeus, 1758) Búbospacsirta - BALI 1983; BANK 1998; FENYÖSI 1993a, 2000; KASZA \& MARIÁN 2001; KÁRPÁtI 1979; Keve 1973, 1975, 1978; MajER I992b; Marlán \& Puskás 1985; NAGY \& Pintér 1994, Purger 1998a.

182. Lullula arborea (Linnaeus, 1758) - Erdei pacsirta - FENYŐSI 1993a, 2000; KÁRPÁTI 1979; Keve 1978; Marlán \& PusKás 1985; NAGY \& Pintér 1994, Purger 1998a.

183. Alauda arvensis Linnaeus, 1758 - Mezei pacsirta - BANK 1998; FENYÓSI 1993a, 2000; KASZA \& MARIÁN 2001; KÁRPÁTI 1979; Keve 1973, 1975, 1978; MAjer 1992b; NAGY \& Pintér 1994; Novotny 1996; Purger 1998a; UJVÁRY 1917

\section{Hirundinidae - Fecskefélék}

184. Riparia riparia (Linnaeus, 1758) - Partifecske - BALI 1983; BANK 1998; FENYÖSI 1993a, 2000; FILOTÁs 1996; KASZA \& MARIÁN 2001; KeVE 1973, 1975, 1978; MAJer 1992a; MARIÁN \& Puskás 1985; NAGY \& Pintér 1994; Purger 1998a; Tevely 1996; Vöröss 1986.

185. Hirundo rustica Linnaeus, 1758 - Füsti fecske - BALI 1983; BANK 1998; FENYÖSI 1993a, 2000; GYUlai 1904; Kasza \& MarIÁN 2001; KÁRPÁti 1979; KeVE 1973, 1975, 1978; MajeR 1992a, 1992b; MARIÁN 1957, 1959; MARIÁN \& PusKás 1985; NAGY \& Pintér 1994; PuRger 1998a; TeVELy 1996; UjVÁRY 1917; VÖRÖSS 1986.

186. Delichon urbica (Linnaeus, 1758) Molnárfecske - BALI 1983; BANK 1998; FENYÓSI 1993a, 2000; FeNYŐSI et. al. 1995; Kasza \& Marián 2001; Kárpáti 1979; Keve 1973, 1978; MAJER 1992a, 1992b; MARIÁN 1957, 1959; MaruÁN \& PusKás 1985; NAGY \& Pintér 1994; PURger 1998a; RéKÁSI 1975; Tevely 1996; TilesCh 1986a; Ujváry 1917; VÖRÖSS 1986.

\section{Motacillidae - Billegetőfélék}

187. Anthus campestris (Linnaeus, 1758) Parlagi pityer - BANK 1998; KeVE 1973, 1978; 
NAGiY \& PinTér 1994, Purger I998a.

188. Anthus trivialis (Linnaeus, 1758) - Erdei pityer - BANK 1998; FenYÓSI 1993a, 2000; Kasza \& Marián 2001; KárpátI 1979; Keve 1973, 1975, 1978; MAJER 1992a, 1992b; Mardán 1957, 1959; Marián \& Puskás 1985; Nagy \& Pintér 1994; Purger 1998a; Tevely 1996.

189. Anthus pratensis (Linnaeus, 1758) Réti pityer - BANK 1998; FENYŐsI 1993a, 2000; KASZA \& Marián 2001; KeVE 1973, 1975, 1978; MARIÁN \& PUSKÁS 1985; NAGY \& PINTÉr 1994.

190. Anthus cervinus (Pallas, 1811) - Rozsdástorkú pityer - BANK 1998; MOLNÁR 1982b, 1982c; FENYŐs! 1993a, 2000; MOLNÁR 1988b; NaGY \& Pintér 1994; SCHENK 1918.

191. Anthus spinoletta (Linnaeus, 1758) Havasi pityer - BANK 1998; KASZA \& MARIÁN 2001; KEVE 1973, 1975, 1978; MOLNÁR 1982c, 1982h, 1984a, 1988b; NAGY \& PiNTÉr 1994.

192. Motacilla flava Linnaeus, 1758 - Sárga billegető - BANK 1998; FENYŐSI 1993a, 2000; HORVÁTH 1960; KASZA \& MARIÁN 2001; KEVE 1973, 1975, 1978; Majer 1992a; Maruán \& Puskás 1985; NAGY \& PINTÉr 1994; NoVOTNY 1996; PURGER 1998a.

193. Motacilla cinerea Tunstall, 1771 - Hegyi billegetô - BANK 1998; FENYÖSI 1993a, 2000; Kasza \& Marián 200I; Keve 1973, 1975, 1978; NAGY \& PINTÉR 1994.

194. Motacilla alba Linnaeus, 1758 - Barázdabillegetố - BALI 1983; BANK1985, 1998; FENYÖSI 1993a, 2000; KASZA \& MARIÁN 2001; KÁrpóti 1979; KeVE 1973, 1975, 1978; Majer 1992a, 1992b; MARIÁN 1957, 1959; MARIÁN \& Puskás 1985; NAGY \& Pintér 1994; Purger 1998a; TeVely I996; UjVÁRY 1917.

\section{Bombycillidae - Csonttollúfélék}

195. Bombycilla garrulus (Linnaeus, 1758) Csonttollú - BANK 1998; B. B. 1924; FENYŐSI 1993a, 2000; KeVE 1978; MOLNÁR 1982d; NAGY \& PINTÉR 1994.

\section{Troglodytidae - Ökörszemfélék}

196. Troglodytes troglodytes (Linnaeus, 1758) - Ökörszem - BANK 1998; FENYÖSI 1993a, 2000; Kasza \& MARIÁN 2001; KárPÁTI 1979; Majer 1992a, 1992b; Marlán 1957, 1959; Marián \& Puskás 1985; KeVE 1973, 1975, 1978; NAgY \& Pintér 1994; Purger 1998a; TEVELy 1996.

\section{Prunellidae - Szürkebegyfélék}

197. Prunella modularis (Linnaeus, 1758) Erdei szürkebegy - BANK 1998; FENYÖSI 1993a,
2000; KASZA \& MARIÁN 2001; KeVE 1973, 1978; NAGi \& Pintér 1994; Purger 1998a.

198. Prunella collaris (Scopoli, 1769) - Havasi szürkebegy - FENYŐSI 2000; HADARICS 1996a.

\section{Turdidae - Rigófélék}

199. Erithacus rubecula (Linnaeus, 1758) Vörösbegy - BALI 1983; BANK 1998; FENYÖSI 1993a, 2000; KASZA \& MARIÁN 2001; KárPáTI 1979; Keve 1973, 1975, 1978; MAjer 1992a, 1992b; MARIÁN 1957, 1959; MARIÁN \& Puskás 1985; NAGY \& Pintér 1994; Purger 1998a; Tevely 1996.

200. Luscinia luscinia (Linnaeus, 1758) Nagy fülemüle - BANK 1998; FENYÖSI 1993a, 2000; MARIÁN \& PUSKÁS 1985; NAGY \& PINTÉR 1994.

201. Luscinia megarhynchos C. L. Brehm, 1831 - Fülemüle - BALI 1983; FenYŐsI 1993a, 2000; KASZA \& MARIÁN 2001; KÁRPÁTl 1979; KeVE 1978; MAIER 1992a, 1992b; MARIÁN 1957, 1959; MARIÁN \& PUSKás 1985; NAGY \& Pintér 1994; Purger 1998a; Tevely 1996; UjVÁRY 1917.

202. Luscinia specica (Linnaeus, 1758) Kékbegy - KeVE 1973, 1975, 1978; NAGY \& PinTÉr 1994; SCHENK 1918.

203. Phoenicurus ochruros (S. G. Gmelin, 1774) - Házi rozsdafarkú - BALI 1983; BANK 1998; FENYŐSI 1993a, 2000; KASZA \& MARLÁN 2001; KÁrpátr 1979; Keve 1978; NAGY \& Pintér 1994; Purger 1998a; TeVely 1996.

204. Phoenicurus phoenicurus (Linnaeus, 1758) - Kerti rozsdafarkú - BANK 1998; KASZA \& Marián 2001; KeVE 1973, 1978; Majer 1992b; Marián 1957, 1959; Nagy \& Pintér 1994.

205. Saxicola rubetra (Linnaeus, 1758) Rozsdás csuk - BANK 1998; FENYÖSI 1993a, 2000; KÁRPÁti 1979; KeVE 1973, 1978; NAGY \& Pintér 1994; Novotny 1996; Purger $1998 \mathrm{a}$.

206. Saxicola torquata (Linnaeus, 1766) Cigánycsuk - BANK 1998; FENYŐSI I993a, 2000; KASZA \& MARIÁN 2001; KÁRPÁTI 1979; Keve 1973, 1975, 1978; Keve \& PátKai 1961; MAJER 1992a, 1992b; MARIÁN 1957, 1959; MARIÁN \& PUSKás 1985; NAGY \& PINTÉr 1994; Purger 1998a; TeVely 1996.

207. Oenanthe oenanthe (Linnaeus, 1758) Hantmadár - BANK 1998; FENYÖSI 1993a, 2000; KeVE 1973, 1978; MarláN \& PUSKás 1985; NAGY \& Pintér 1994; PURGer 1998a. 208. Monticola saxatilis (Linnaeus, 1766) Kövirigó - KeVE 1978. 
209. Turdus torquatus Linnaeus, 1758 - Örvös rigó - HADARICS 1996d; KASZA \& MARIÁN 2001; Keve 1978; Keve \& PÁtKaI 1961; MOLNÁR 1982h; NAGY \& PinTér 1994.

210. Turdus merula Linnaeus, 1758 - Fekete rigó - BALI 1983; BANK 1998; BARTOS 1906b; FENYÖSI 1993a, 2000; KASZA \& MARLÁN 2001; Kárpót 1979; KeVE 1973, 1975, 1978; MAjer 1992a, 1992b; MARIÁN 1957, 1958b, 1959; MARIÁN \& Puskás 1985; NAGY \& Pintér 1994; Purger 1998a; Tevely 1996.

211. Turdus pilaris Linnaeus, 1758 - Fenyôrigó - BANK 1998; BARTOS 1905; FENYÖSI 1993a, 2000; KASZA \& MARIÁN 2001; KáRPÁTI 1979; KEVE 1973, 1975, 1978; MARIÁN \& Puskás 1985; NAGY \& Pintér 1994; Purger $1998 \mathrm{a}$

212. Turdus philomelos C. L. Brehm, 1831 Énekes rigó - BANK 1998; FENYÖSI I993a, 2000; KASZA \& MARIÁN 2001; KÁRPÁTI 1979; Keve 1973, 1975, 1978; Majer 1992a, 1992b; MARiÁN \& Puskás 1985; NAGY \& Pintér 1994; Purger 1998a; Tevely 1996.

213. Turdus iliacus Linnaeus, 1766 - Szőlörigó - BANK 1998; FENYÖSI 1993a, 2000; HADARICS 1996d, 1997a, 1998a, 1999; KASZA \& Marí́n 2001; KeVE 1973, 1978; Marián \& PUSKÁS 1985; MOLNÁR 1982b, 1982c, 1982h; NAGY \& PINTÉr 1994.

214. Turdus viscivorus Linnaeus, 1758 - Léprigó - BANK 1998; BARTOS 1906b; FENYÖSI 1993a, 2000; KASZA 1983b; KASZA \& MARIÁN 2001; KÁrPátI 1979, 1980; KeVE 1978; Marián \& Puskás 1985; NAGY \& Pintér 1994; Purger 1998a; Tevely 1996.

\section{Sylviidae - Poszátafélék}

15. Locustella naevia (Boddaert, 1783) - Réti tücsökmadár - BANK 1998; FENYŐSI 1993a, 1994a, 2000; KASZA \& MARIÁN 2001; KEVE 1973, 1975, 1978; MAJER 1992a; NAGY \& Pintér 1994; Novotny 1996; Purger 1998a.

216. Locustella flupiatilis (J. F. Wolf, 1810) Berki tücsökmadár - BANK 1998; FENYÖSI 1993a, 2000; KASZA 1982a, 1983d; KASZA \& MARIÁN 2001; KárpátI 1979, 1980; KeVE 1978; MAJER 1992a, 1992b; MARIÁN 1957, 1958b, 1959; MARIÁN \& PUSKÁs 1985; NAGY \& Pintér 1994, Purger 1998a.

217. Locustella luscinioides (Savi, 1824) - Nádi tücsökmadár - FENYÖSI 1993a, 2000; KASZA \& Marián 200I; KÁrpáti 1979; Keve 1973, 1975, 1978; MAJER 1992a, 1992b; NAGY \& PINTÉr 1994; PURGer 1998a.
218. Acrocephalus melanopogon (Temminck, 1823) - Fülemülestike - KEVE 1973, 1975, 1978; MAjer 1992a; NAGY \& Pintér 1994; SCHENK 1918.

219. Acrocephalus paludicola (Vieillot, 1817) Csíkosfejú nádiposzáta - KEvE 1973, 1978.

220. Acrocephalus schoenobaenus (Linnaeus, 1758) - Foltos nádiposzáta - BANK 1998; FENYŐSI 1993a, 2000; KASZA \& MARIÁN 2001; KÁrPÁTI 1979; KeVE 1973, 1975, 1978; MAJER 1992a, 1992b; NAGY \& PINTÉR 1994; PURGeR 1998a; TEVELy 1996.

221. Acrocephalus palustris (Bechstein, 1798) - Énekes nádiposzáta - BANK 1998; FENYÓSI 1993a, 2000; KASZA \& MARIÁN 2001; KÁrPÁt 1979; KeVE 1973, 1975, 1978; MAjer I992a; NagY \& Pintér 1994; Purger 1998a; Tevely 1996.

222. Acrocephalus scirpaceus (J. Hermann, 1804) - Cserregó nádiposzáta - BANK 1998; FENYŐSI 1993a, 2000; KASZA \& MARIÁN 2001; Keve 1973, 1975, 1978; Majer 1992a, 1992b; Marián 1957, 1959; Marián \& Puskás 1985; NaGy \& Pintér 1994, Purger I998a; Tevely 1996.

223. Acrocephalus arundinaceus (Linnaeus, 1758) - Nádirigó - BALI 1983; BANK 1998; FENYösI 1993a, 2000; KASZA \& MARLÁn 2001; KÁrpÁtI 1979; KeVE 1973, 1975, 1978; MAJER 1992a, 1992b; MARIÁN 1957, 1959; NAGY \& Pintér 1994; Purger 1998a; Tevely 1996.

224. Hippolais icterina (Vieillot, 1817) Kerti geze - BANK 1998; FenYŐSI 1993a, 2000; KASZA \& MarIáN 2001; Keve 1978; Marián \& Puskás 1985; NAGY \& PinTÉr 1994.

225. Sylvia nisoria (Bechstein, 1795) Karvalyposzáta - BANK 1998; FeNYÖSI 1993a, 2000; Kasza \& Marián 2001; KeVE 1973, 1978; Marián \& Puskás 1985; Nagy \& Pintér 1994; PURGer 1998a.

226. Sylvia curruca Linnaeus, 1758 - Kis poszáta - BANK 1998; FENYÓSI 1993a, 2000; KASZA \& MARIÁN 2001; KÁrPÁTI 1979; KeVE 1973, 1975, 1978; MAJER 1992a, 1992b; Marián 1957, 1959; Marián \& Puskás 1985; NAGy \& Pintér 1994; Purger 1998a; TeVely 1996.

227. Sylvia communis Latham, 1787 - Mezei poszáta - BANK 1998; FENYÓSI 1993a, 2000; KASZA \& MARIÁN 2001; KÁRPÁTI 1979; KeVE 1973, 1975, 1978; MAJER 1992a, 1992b; Marián 1957, 1959; NAGY \& Pintér 1994; PURGER 1998a.

228. Sylvia borin (Boddaert, 1783) - Kerti poszáta - BANK 1998; FENYŐSI 1993a, 2000; Kasza \& Marián 2001; Keve 1978; Majer 1992a, 1992b; NagY \& PinTér 1994. 
229. Sylvia atricapilla (Linnaeus, 1758) Barátposzáta - BALI 1983; BANK 1998; FENYÖSI 1993a, 2000; KASZA \& MARIÁN 2001; KáRPÁTI 1979; KeVE 1975, 1978; MAJER 1992a, 1992b; MARIÁN \& PusKás 1985; NAGY \& PinTÉR 1994; Purger 1998a; SCHenk 1918; Tevely 1996.

230. Phylloscopus bonelli (Vieillot, 1819) Bonelli füzike - NAGY \& PINTÉR 1994.

231. Phylloscopus sibilatrix (Bechstein, 1793) - Sisegó füzike - BANK 1998; FENYÔSI 1993a, 2000; KASZA 1983c, 1984; KASZA \& MARIÁN 2001; KáRPÁTI 1979; KeVE 1975, 1978; MAJER 1992a, 1992b; NAGY \& PINTÉR 1994; Purger 1998a; TeVely 1996.

232. Phylloscopus collybita (Vieillot, 1817) Csilpcsalpfüzike - BALI 1983; BANK 1998; FENYŌSI 1993a, 2000; KASZA \& MARIÁN 2001; KÁRPÁTI 1979; KEVE 1973, 1975, 1978; MAJER 1992a, 1992b; MARIÁN 1957, 1959; MARIÁN \& Puskás 1985; NAGY \& Pintér 1994; Purger 1998a; TEVELY 1996.

233. Phylloscopus trochilus (Linnaeus, 1758) - Fitiszfüzike - BANK 1998; FeNYöSI 1993a, 2000; KASZA \& MARIÁN 2001; KárPÁTI 1979; Keve 1973, 1975, 1978; Majer 1992b; MARIÁN 1957, 1959; MARIÁN \& PUSKÁs 1985; NAGY \& PINTÉR 1994.

234. Regulus regulus (Linnaeus, 1758) - Sárgafejú királyka - BANK 1998; FENYŐSI 1993a, 2000; KASZA \& MARIÁN 2001; KÁRPÁTI 1979; KeVe 1973, 1975, 1978; NAGY \& PINTÉR 1994; PURGER 1998a.

235. Regulus ignicapillus (Temminck, 1820) Tüzesfejú királyka - BANK 1998; FENYŐSI 1993a, 2000; KEVE 1978; MOLNÁR 1985, 1988b; Nagy \& Pintér 1994.

\section{Muscicapidae - Légykapófélék}

236. Muscicapa striata (Pallas, 1764) - Szürke légykapó - BALı 1983; BANK 1998; FENYÖSI 1993a, 2000; KASZA \& MARIÁN 2001; Keve 1973, 1978; MAJER 1992a, 1992b; MARIÁN \& Puskás 1985; NAGY \& Pintér 1994; PuRger I998a; TEVELY 1996; UJVÁRY 1917.

237. Ficedula parva (Bechstein, 1794) - Kis légykapó - KEVE 1978; NAGY \& PINTÉR 1994.

238. Ficedula albicollis (Temminck, 1815) Örvös légykapó - BANK 1998; FeNYöSI 1993a, 2000; KASZA \& MARIÁN 2001; KáRPÁTI 1979; KeVE 1978; Majer 1992a, 1992b; MarláN 1957, 1959; MARJÁN \& PUSKás 1985; NAGY \& PinTÉr 1994; PURGER 1998a.

239. Ficedula hypoleuca (Pallas, 1764) - Kormos légykapó - BANK 1998; BARTOS 1906e; FENYŐSI 1993a, 2000; KASZA \& MARJÁN 2001;
KeVE 1978; MAjer 1992a; MolnÁr 1985, 1988b; NAGY \& PINIÉR 1994; PURGER 1998a.

\section{Timaliidae - Timáliafélék}

240. Panurus biarmicus (Linnaeus, 1758) Barkóscinege - FenYósı 1993a, 2000; KASZA \& MARIÁN 2001; KeVE 1973, 1975, 1978; NAGY \& PINTÉR 1994; SCHENK 1918.

\section{Aegithalidae - Ószapófélék}

241. Aegithalos cadatus (Linnaeus, 1758) Öszapó - BALI 1983; BANK 1998; FENYÖSI 1993a, 2000; KASZA \& MARIÁN 2001; KÁRPÁTI 1979; KEVE 1978; MAJER 1992a, 1992b; MARIÁN 1957, 1959; MARIÁN \& PUSKÁS 1985; NaGy \& Pintér 1994; Purger 1998a; TeVely 1996.

\section{Paridae - Cinegefélék}

242. Parus palustirs Linnaeus, 1758 - Barátcinege - BANK 1998; BARTOS 1906a; FenYöSI 1993a, 2000; KASZA \& MARIÁN 2001; KÁRPÁTI 1979; KEVE 1978; MAJER 1992a, 1992b; MARIÁN 1957, 1958b, 1959; MARIÁN \& Puskás 1985; Nagy \& Pintér 1994; Purger 1998a; TeVely 1996; TilesCh 1986b.

243. Parus cristatus Linnaeus, 1758 - Búbos cinege - FeNYÖSI 1993a, 2000; FERENCZ 1965; GYÖRGYPÁl 1978; KASZA 1982b; KASZA \& MARLÁn 2001; KÁRPÁTI 1979, 1980; MAjER 1992b; MARú́N \& PUSKÁS 1985; MOLNÁR 1982b, 1982h, 1988b; NAGY \& PINTÉR 1994; TeVely 1996.

244. Parus ater Linnaeus, 1758 . Fenyvescinege - BANK 1998; FENYÕSI 1993a, 2000; FERENCZ 1965; GYörGYPÁL 1978; KASZA 1982b; Kasza \& Marián 2001; Kárpáti 1979, 1980; KEVE 1978; MAJER 1992b; MARIÁN \& PUSKÁS 1985; NAGY \& Pintér 1994; PURGeR 1998a.

245. Parus caeruleus Linnaeus, 1758 - Kék cinege - BANK 1998; FENYÖSI 1993a, 2000; KasZa \& Marián 2001; Kárpáti 1979; KeVE 1973, 1975, 1978; MAJER 1992a, 1992b; MARIÁN 1957, 1959; MARIÁN \& PUSKÁS 1985; NAGY \& Pintér 1994; Purger 1998a; Tevely 1996; TILESCH 1986a.

246. Parus major Linnaeus, 1758 - Széncinege - BALI 1983; BANK 1998; FENYÖSI 1993a, 2000; KASZA \& MarIÁN 2001; KárPÁTI 1979; Keve 1973, 1975, 1978; Majer 1992a, 1992b; MARIÁN 1957, 1958b, 1959; MARIÁN \& Puskás 1985; Nagy \& Pintér 1994; Purger I998a; SZIKIA 1895; Tevely 1996.

\section{Sittidae - Csuszkafélék}

247. Sitta europaea Linnaeus, 1758 - Csuszka - BALI 1983; BANK 1998; FENYŐSI 1993a, 2000; Kasza \& Marián 2001; Kárpáti 1979; 
KeVE 1978; MAJER 1992a, 1992b; MARIÁN 1957, 1959; MARIÁN \& PUSKÁS 1985; NAGY \& PiNTÉr 1994; Purger 1998a; TeVely 1996.

Tichodromidae - Hajnalmadárfélék

248. Tichodroma muraria (Linnaeus, 1766) Hajnalmadár - KEVE 1978.

\section{Certhiidae - Fakúszfélék}

249. Certhia familiaris Linnaeus, 1758 - Hegyi fakúsz - BANK 1998; FENYŐsI 1993a, 2000; KeVE 1978; MAJer 1992a; NAGY \& Pintér 1994; PURGER 1998a.

250. Certhia brachydactyla C. L. Brehm, I820 - Rövidkarmú fakúsz - BANK 1998; FENYŐ́SI 1993a, 2000; KASZA \& MARIÁN 2001; KÁrPÁTI 1979; KeVE 1978; MARIÁN \& PUSKÁS 1985; NAGY \& PinTér 1994; Purger 1998a.

\section{Remizidae - Függő́cinege-félék}

251. Remiz pendulinus (Linnaeus, 1758) Függócinege - BANK 1998; FENYÖSI 1993a, 2000; KASZa \& Marián 2001; KeVe 1973, 1975, 1978; MAJER 1992a; MARIÁN \& PUSKÁS 1985; NAGY \& PiNTÉr 1994; PURGer 1998a; Sára 1970a.

\section{Oriolidae - Sárgarigófélék}

252. Oriolus oriolus (Linnaeus, 1758) - Sárgarigó - BANK 1998; FENYÖSI 1993a, 2000; KASZA \& MARIÁN 2001; KÁRPÁTI 1979; KeVE 1973, 1975, 1978; MAJER 1992a, 1992b; MARJÁN 1957, 1959; MARJÁN \& PUSKÁS 1985; NaGy \& Pintér 1994; PURGer 1998a; Tevely 1996; UJVÁRY 1917.

\section{Laniidae - Gébicsfélék}

253. Lanius collurio Linnaeus, 1758 Töviszúró gébics - BALI 1983; BANK 1998; BARTOS 1906b; FENYŐSI 1993a, 2000; HOMONAY 1959b; KASZA \& MARIÁN 2001; KÁRPÁTI 1979; Keve 1973, 1975, 1978; MAjER 1992a, 1992b; MARIÁN 1957, 1958b, 1959; MARIÁN \& PUSKÁS 1985; NAGY \& PinTÉr 1994; PURGer 1998a; TeVELy 1996.

254. Lanius minor J. F. Gmelin, 1788 - Kis örgébics - KeVE 1973, 1975, 1978; NAGY \& PINTÉR 1994.

255. Lanius excubitor Linnaeus, 1758 - Nagy órgébics - BANK1985, 1998; BARTOS 1906e; FENYÖSI 1993a, 2000; KASZA \& MARIÁN 2001; KÁRPÁtI 1979; KeVE 1973, 1975, 1978; MARIÁN \& PUSKÁS 1985; MOLNÁR 1982e, 1982f, 1983, 1984a, 1988b; NAGY \& PINTÉR 1994; PURger 1998a.
256. Lanius senator Linnaeus, 1758 Vörösfejú gébics - BARTHOS 1942; SÁRA 1970a; SCHENK 1918.

\section{Corvidae - Varjúfélék}

257. Garrulus glandarius (Linnaeus, 1758) Szajkó - BANK 1998; BARTHOS 1958; FENYÖSI 1993a, 2000; KASZA \& MARIÁN 2001; KárPÁTI 1979; KeVE 1975, 1978; MAJER 1992a, 1992b; MARIÁN 1957, 1958b, 1959; MARIÁN \& Puskás 1985; Purger 1998a; TeVely 1996.

258. Pica pica (Linnaeus, 1758) - Szarka BANK 1998; BARTOS 1906b; Fallon-Kund 1937; FENYÖSI 1993a, 2000; KASZA \& MARIÁN 2001; KÁRPÁtI 1979; KeVE 1973, 1975, 1978; MAjER 1992a, 1992b; MARIÁN \& PUSKÁs 1985; PURGer 1998a.

259. Nucifraga caryocatactes (Linnaeus, 1758) - Fenyőszajkó - SCHENK 1918.

260. Corvus monedula Linnaeus, 1758 - Csóka - BALI 1983; BANK 1998; BARTOS 1906b; FENYÖSI 1993a, 2000; KASZA \& MARIÁN 2001; KEVE 1973, 1975, 1978; MAJER 1992a; MARIÁN 1957; MARIÁN \& PUSKÁS 1985; MERÉSZ 1996; NAGY \& Pintér 1994; PURGeR 1998a.

261. Corvus frugilegus Linnaeus, 1758 - Vetési varjú - BANK 1998; FeNYÓSI 1993a, 2000; KALOTÁS 1982, 1985, 1988; KASZA \& MARIáN 2001; KÁrPÁTI 1979; KeVE 1973, 1975, 1978; PURGER 1998a.

262. Corvus corone Linnaeus, 1758 - Kormos varjú / Dolmányos varjú

Corvus corone corone Linnaeus, 1758 - Kormos varjú - HAVRANEK 1995; HAVRANEK et. al. 1995a.

Corvus corone cornix Linnaeus, 1758 - Dolmányos varjú - BALI 1983; BANK 1998; BARTOS 1906b; Fallon-Kund 1937; FENYÖSI 1993a, 2000; HAVRANeK et. al. 1995a; KASZA \& MARIÁN 2001; KÁRPÁTI 1979; KEVE 1973, 1975, 1978; MAJER 1992a, 1992b; MARIÁN \& PUSKÁs 1985; MOLNÁR 1982h; NAGY \& PINTÉR 1994; PURGER 1998a.

263. Corvus corax Linnaeus, 1758 - Holló BARTHOS 1947; FENYÖSI 1993a, 2000; HAVRANEK 1995; KASZA \& MARIÁN 2001; Kárpáti 1979; KeVE 1978; Majer 1992a; MARIÁN 1957, 1958a, 1958b, 1959; MARIÁN \& Puskás 1985; NAGY \& Pintér 1994; Purger 1998a; TILESCH 1986c; SZEmere 195l; SZÉCHENYI 1942; TEVELY 1996.

\section{Sturnidae - Seregélyfélék}

264. Sturnus vulgaris Linnaeus, 1758 - Seregély - BALI 1983; BANK 1998; BARTOS 1906b; FENYŌSI 1993a, 2000; KASZA \& MARIÁN 2001; 
KÁRPÁTI 1979; MAJER 1992a, 1992b; MARLÁN 1957, 1959; MARLÁN \& PUSKÁS 1985; KeVE 1973, 1975, 1978; PURGer 1998a; TeVELY 1996; UJVÁRY 1917.

265. Pastor roseus (Linnaeus, 1758) - Pásztormadár - KeVE 1978; NAGY \& PINTÉR 1994; SCHENK 1918.

\section{Passeridae - Verébfélék}

266. Passer domesticus (Linnaeus, 1758) Házi veréb - BALI 1983; BANK 1998; BarTos 1906b; FENYÖSI 1993a, 2000; KALOTÁS 1989; Kasza \& Marlán 200I; Kárpáti 1979; KeVE 1973, 1978; MAJER 1992a, 1992b; PURger 1998a; TeVely 1996.

267. Passer montanus (Linnaeus, 1758) Mezei veréb - BANK 1998; Bartos 1906b; FENYÖSI 1993a, 2000; KALOTÁs 1989; KASZA \& Marián 2001; KáRPÁtI 1979; KeVE 1973, 1975, 1978; MAJER 1992a, 1992b; PURGER 1998a; Tevely 1996.

\section{Fringillidae - Pintyfélék}

268. Fringilla coelebs Linnacus, 1758 - Erdei pinty - BALI 1983; BANK 1998; FENYÖSI 1993a, 2000; KASZA \& MARIÁN 200I; KÁRPÁTI 1979; KeVE 1973, 1975, 1978; Majer 1992a, 1992b; MARIÁN 1957, 1959; MARIÁN \& PUSKás 1985; NAGY \& Pintér 1994; Purger 1998a; Tevely 1996.

269. Fringilla montifringilla Linnaeus, 1758 . Fenyőpinty - BANK 1998; FENYŐSI 1993a, 2000; KaSZa \& Maruán 2001; KeVe 1973, 1975, 1978; Marlán \& PusKás 1985; NaGY \& Pintér 1994; Purger 1998a.

270. Serinus serinus (Linnaeus, 1766) Csicsörke - BaLI 1983; BANK 1998; FeNYósI 1993a, 2000; KALOTÁS 1989; KASZA \& MARIÁN 2001; Keve 1973, 1978; Marián \& Puskás 1985; NAGY \& Pintér 1994; Purger 1998a.

271. Carduelis chloris (Linnaeus, 1758) Zöldike - BALI 1983; BANK 1998; FENYÖSI 1993a, 2000; KASZA \& MARIÁN 2001; KÁrPÁTI 1979; KeVE 1973, 1975, 1978; MAJER 1992a, 1992b; MARIÁN \& PUSKÁS 1985; NAGY \& Pinrér 1994; Purger 1998 a; 'T'Evely 1996.

272. Carduelis carduelis (Linnaeus, 1758) Tengelic - BALI 1983; BANK 1998; FENYÖSI 1993a, 2000; KASZA \& Marián 2001; KÁrPÁTI 1979; Keve 1973, 1975, 1978; MAJER 1992a; NaGy \& Piniér 1994; Purger 1998a; Tevely 1996.

273. Carduelis spinus (Linnaeus, 1758) Csíz - Bank 1998; FenYósı 1993a, 1994b, 2000; KASZA \& MARIÁN 2001; KÁRPÁTI 1979;
KeVE 1973, 1975, 1978; NAGY \& PINTÉr 1994; PURGer 1998a.

274. Carduelis cannabina (Linnaeus, 1758) Kenderike - BANK 1998; FENYÖSI 1993a, 2000; KASZA \& MARIÁN 2001; KÁrPÁTI 1979; KEVE 1978; Nagy \& Pintér 1994; Purger 1998a; Tevely 1996.

275. Carduelis flavirostris (Linnaeus, 1758) Sárgacsórü kenderike - KEVE 1973, 1978.

276. Carduelis flammea (Linnaeus, 1758) Zsezse - FenYÖSI 1993a, 2000; KASZA \& Marlán 2001; KeVE 1973, 1975, NaGy \& PinTér 1994; SCHENK 1918.

277. Loxia cunirostra Linnaeus, 1758 - Keresztcsốrü - FENYŐsI 1993a, 2000; GRESCHIK 1909; HoRvÁth \& NaGY 1994; KeVE 1978; molnár 1988b; Nagy \& Pintér 1994.

278. Carpodacus erythrinus (Pallas, 1770) Karmazsinpirók - NAGY \& PINTÉr 1994; Stollmann et. al. 1987.

279. Pyrrhula pyrrhula (Linnaeus, 1758) Süvöltô - BANK 1998; FeNYÖSı 1993a, 2000; Kasza \& Marión 2001; Kúrpáti 1979; Keve 1973, 1975, 1978; NAGY \& PinTér 1994; PURGER 1998a.

280. Coccothraustes coccothraustes (Linnaeus, 1758) - Meggyvágó - BANK 1998; FENYỐSI 1993a, 2000; KASZA \& MARIÁN 2001; KárPÁTI 1979; Keve 1978; Majer 1992a, 1992b; MArí́N 1957, 1959; MARIÁN \& Puskés 1985; Nagy \& Pintér 1994; Purger 1998a; Tevely 1996.

\section{Emberizidae - Sármányfélék}

281. Plectrophenax nivalis (Linnaeus, 1758) Hósármány - FENYÓSI 2000; TILESCH 1986c.

282. Emberiza citrinella Linnaeus, I758 Citromsármány - BANK 1998; FENYÖSI 1993a, 2000; KASZA \& MARIÁN 2001; KÁRPÁTI 1979; KEVE 1973, 1978; MAJER 1992a, 1992b; MARIÁN 1957, 1958a, 1959; MARIÁN \& PUSKÁS 1985; NAGY \& Pintér 1994; PURGer 1998a; Tevely 1996.

283. Emberiza schoeniclus (Linnaeus, 1758)Nádi sármány - BANK 1998; FENYÖSI 1993a, 2000; Kasza \& MarIán 2001; Keve 1973, 1975, 1978; NACiY \& Piniér 1994; PURGer 1998a.

284. Miliaria calandra (Linnaeus, 1758). Sordély - BANK 1998; FENYÖSI 1993a, 2000; Kárpáti 1979; Keve 1973, 1975, 1978; MaJer 1992a; Nagy \& Pintér 1994; Purger 1998a; TeVely 1996. 
Somogy megyében az eddigi adatok alapján 284 madárfaj előfordulásáról van tudomásunk, ami a magyar ornitofauna 76 \%-ának felel meg. Magyarország és Somogy megye madárfaunájának összevetését táblázat segíti (1. táblázat). A fajlista és az irodalomjegyzék nem tekinthetố véglegesnek és teljesnek, de bízunk abban, hogy az elkezdett munka követőkre talál, és a fehér foltok hamarosan eltúnnek a megye madártani kutatottságának térképéról.

I táblázat: Az egyes rendekbe tartozó fajok számának megoszlása Magyarországon és Somogy megyében

Table 1.: Species numbers of various orders; their distributionin Hungary and Somogy county

\begin{tabular}{|l|c|c|}
\hline $\begin{array}{l}\text { Rend } \\
\text { Order }\end{array}$ & $\begin{array}{c}\text { Magyarország } \\
\text { Hungary }\end{array}$ & $\begin{array}{c}\text { Somogy megye } \\
\text { Somogy county }\end{array}$ \\
\hline Gaviiformes & 3 & 3 \\
\hline Podicipediformes & 5 & 5 \\
\hline Pelecaniformes & 4 & 3 \\
\hline Ciconiiformes & 14 & 12 \\
\hline Phoenicopteriformes & 1 & 0 \\
\hline Anseriformes & 38 & 33 \\
\hline Accipitriformes & 26 & 18 \\
\hline Falconiformes & 8 & 7 \\
\hline Galliformes & 6 & 4 \\
\hline Gruiformes & 12 & 10 \\
\hline Charadriiformes & 83 & 57 \\
\hline Pterocliformes & 2 & 0 \\
\hline Columbiformes & 6 & 4 \\
\hline Cuculiformes & 1 & 1 \\
\hline Strigiformes & 12 & 7 \\
\hline Caprimulgiformes & 1 & 1 \\
\hline Apodiformes & 3 & 1 \\
\hline Coraciformes & 4 & 4 \\
\hline Piciformes & 9 & 9 \\
\hline Passeriformes & 135 & 105 \\
\hline Összesen - Total & 373 & 284 \\
\hline
\end{tabular}




\section{Irodalom}

AGí́rdı E. 1935: Küszvágócsér-telep a balatoni Nagyberekben. - Magyar Vadászújság 35: 429-430.

AGÁRDI E. 1968: Dankasirály-telep a balatoni Nagyberekben. - Aquila 75: 287.

ANONYMUS 1906: Éneklố hattyú Somogy megyében. - Zoológiai Lapok, p. 290.

BALI J. 1983: Faunisztikai adatok Balatonföldvárról és környékéról. Mad. Táj. 2: 82-84.

Bank L. 1984: A zöld külló (Picus viridis) etológiáához. - Mad. Táj. 3: 169-170.

BANK L. 1985: Barázdabillegetốt (Motacilla alba) zsákmányoló nagy órgébics (Lanius excubitor). - Mad. Táj. 3: 53.

BANk L. 1989: A billegetoo cankó (Actitis hypoleucos) drávai fészkelése. - Mad. Táj. 3: 169-170.

BANK L.. 1998: A Dráva és Mura folyók Zákány-Murakeresztúr menti területeinek madárfaunisztikai alapvetése. - Tenkes 2: 14-39.

BANKOVICS A. 1985: A Balaton átvonuló és teleló vízimadarainak állománybecslése. - Aquila 92: 55-64.

BARTOS GY. 1905: A fenyốrigó és a nyírfa. - Aquila 12: 340.

BARToS Gr. 1906a: Parus palustris helyi kártékonysága. - Aquila 13: 209.

BArtos GY. 1906b: Cserebogarat pusztító madarak. - Aquila 13: 209.

Bartos Gr. 1906c: Coracias garrula. - Aquila 13: 209-210.

BARTos GY. 1906d: Kakukmimicry. Aquila 13: 218.

BARTOS Gy. 1906e: Lanius excubitor, Muscicapa atricapilla, Asio accipitrinus. - Aquila 13: 222.

BARTOS GY. 1908: Néhány adat az egerészölyv táplálkozásához. - Aquila 15: 307-308.

BARTOS Gy. 1942: A vörösfejü gébics előfordulása Somogy- és Zala megyében. - Aquila 46-49: 461.

Bartos Gy. 1947: Daruvonulás a Dunántúlon. - Aquila 51-54: 157.

BARTOS Gy. 1951: Bütykös ásólúd Somogyban. - Aquila 55-58: 233.

BArTOS GY.. 1958: Szajkók vonulása. - Aquila 65: 292.

BARTOS T. 1947: A hollók újabb megjelenése Somogy megyében. - $\Lambda$ quila 51-54: 170.

B.B. 1924: Ritkaságok Somogyban. - Nimród Vadászlap 12: 41.

BerzSenyı Z. 1918: A daru fészkelése a balatoni berkekben. - Természettudományi Közlöny 50: 124-125.

BÉCSY L., FENYốSI L. \& HORVÁTH Z. 1995: A kis csér (Sterna albifrons) drávai fészkelése. - Aquila 102: $218-219$.

Breuer Gy. I955a: $\Lambda$ rétisas fészkclése Varászlón. - Aquila 59-62: 379.

Breuer Gy.. 1955b: Gulipán a Balaton vidékén. - Aquila 59-62: 383.

Chernel I. 1921: Jegyzetek a Balaton mellékérôl 1921 öszén. - Aquila 28: 127-130.

Chernel I. 1922: Ugartyúk (Oedicnemus scolopax Gm.) Somogymegyében. - Aquila 28-29: 177.

CSery G. 1929: Túzok Somogyban. - Nimród 17: 137.

Fallon-Kund A. I937: Daru és túzok Somogyban. - Nimród Vadászújság 25: 256.

FALLON-Kund A. 1948: Madártani megfigyelések Somogyfajsz környékéról. - Nimród 35: 94.

FENYÖSı L. 1992: Adatok a fekete harkály (Dryocopus martius) költéséhez. - Mad. Táj. 2: 26.

FENYƠsI L. 1993a: A Barcsi Tájvédelmi Körzet madarai (1983-93). - Állattani Közlemények 79: 55-66.

FENYôsı L. 1993b: Adatok az egerészölyv (Buteo buteo) táplálkozásához. - Mad. Táj. 1: 17.

FENYŐsı L. 1993c: Ragadozómadár-fészkelések a Barcsi TK-ban (1992). - Mad. Táj. 1: 27.

FenYösi L. 1993d: Kis lile (Charadrius dubius) fészkelési adatai. - Mad. Táj. 2: 31-32.

FenYốsı L. 1994a: Adatok a réti tücsökmadár (Locustella naevia) elterjedéséhez. - Mad. Táj. 1: 23.

FenYốsı L. 1994b: Adatok a csíz (Carduelis spinus) nyári eloofordulásaihoz. - Mad. Táj. 2: 24.

FENYÖSI L. 1994c: Réti sas (Haliaetus albicilla) fürdése. - Mad. Táj. 2: 35

FENYÖSI L. 1994d: ^datok a gyöngybagoly (Tyto alba) Somogy megyei táplálkozásához. - Mad. Táj. 2: 30-32.

FENYŐsı L. 1994e: Adatok a fehér gólya (Ciconia ciconia) Somogy megyei fészkelési viszonyaihoz. - Aquila 101: 204-205.

FENYösı L. 1995a: A csörgö réce (Anas crecca) Barcs környékén. - Mad. Táj. 2: 25.

FENYÖsr L. 1995b: A szürke küllô (Picus canus) Dél-Somogyban. - Mad. Táj. 2: 30-31.

FENYösı L. 1996: A Dráva somogyi szakaszának madárvilága (non Passcriformes). - Állattani Közlemények 81: 19-35.

FenYósı L. 1997: Vízivad védelem és -gazdálkodás a somogyi Dráva-szakaszon. - Szakdolgozat, Soproni Egyetem, Vadgazdálkodási Tànszék, p. 1-68. 
FEnYÖSı L. 1998a: Adatok a Duna-Dráva Nemzeti Park somogyi területének fehér gólya (Ciconia ciconia L.) állományához az 1996. évi felmérés alapján. - Dunántúli Dolg. Term. tud. Sorozat 9: $47 \mathrm{I}-474$.

FENYÖSı L. 1998b: A kis csér (Sterna albifrons Paall.) költőhelyei Magyarországon. - Dunántúli Dolg. Term. tud. Sorozat 9: 465-470.

FENYŐsı L. 1998c: Fekete gólya (Ciconia nigra) fészkelési adatok a Barcsi Borókás Tájvédelmi Körzetból (1985-1996). - Aquila 103-104: 115-119.

FENYŐsı L. 1999a: Kanadai lúd (Branta canadensis) megfigyelése a horvátországi Dráván. - Túzok 4(I-2): 25.

FENYÖSI L. 1999b: A Barcsi Borókás vízimadarai és természetvédelmi jelentőségük [Podicipediformes, Anseriformes, Gruiformes (Rallidae)]. - Szakdolgozat, PATE Keszthely, p. 1-44.

FENYÖsI L. 2000: A Barcsi Borókás madarainak bibliográfiája (1937-1999). - Somogyi Múzeumok Közleményei 14: 349-358.

FenYősi L. \& Horváth Z. 2000a: Adatok a fehér gólya (Ciconia ciconia) Somogy-megyei állományához, az 1999. évi felmérés alapján. - Somogyi Múzeumok Közleményei 14: 343-347.

FenYösı L. \& HoRváth Z. 2000b: Csörgö réce (Anas crecca) fészkelése a Barcsi Borókásban. - Túzok (in print).

FEnYŐSI L. \& STIX J. 1993: Adatok az erdei szalonka fészkeléséhez. - Mad. Táj. 2: 38.

FEnYősı L. \& STIX J. 1995: Fekete gólya (Ciconia nigra) fiókájának felnevelése. - Mad. Táj. 1: 8.

FENYŐsI L.\& STIX J. 1996: Nagy kócsagot (Egretta alba) támadó héja (Accipiter gentilis). - Túzok I(4): 185.

FENYŐsI L. \& STIX J. 1998: Megjegyzések a „Rétisas (Haliaeetus albicilla) által nevelt egerészölyv (Buteo buteo) fiókák“" címú íráshoz. - Túzok 3(2): 64-65.

FenYösi L., Horváth Z. \& Pintér A. 1995: A gyöngybagoly (Tyto alba) Belső-Somogyban. MME IV. - Tudományos Ülésének összefoglalói, Nyíregyháza (Poszter).

FenYösi L., HorvÁth Z. \& PinTér A. 1998: Adatok a gyöngybagoly (Tyto alba) Somogy megyei elterjedéséhez az 1995. évi felmérés alapján. - Aquila 103-104: 131-133.

FenYôsi L., Koppán A. \& Winkler D. 1995: MolnÁrfecske (Delichon urbica) telep Barcson. Mad. Táj. 2: 32.

Ferencz M. 1965: Fenyves és búbos cinege állomány Barcs környékén. - Aquila 71-72: 229.

FILOTÁs Z. 1996: Somogyi fáslegelók és jelentóségük. - Anser 3: 31-40.

FILOTÁs Z. 2000: A vízivad védelme és gazdálkodás Belső-Somogy vizes élóhelyein, különös tekintettel a cigányréce (Aythya nyroca) állományára. Szakdolgozat, Soproni Egyetem, Vadgazdálkodási Intézet, p. 1-78.

FöLDVÁRY M. 1929: A Baláta-tó. - Kócsag 1: 10-12.

FöldVÁRY M. 1938: Fako keselyú. - Aquila 42-45: 672.

GRESCHIK J. 1909: A keresztcsőrú tömeges megjelenése Magyarországon. - Aquila 16: 299-305.

GRESCHIK J. 1929: Parkba telepedő örvösgalambpár Kaposvárott. - Kócsag 2: 85-86.

GYENEI F. \& SZABÓ B. 1995: Félrenyelés okozta elhullás hegyi récénél (Aythya marila). - Anser 1: 30.

GYENEI F. \& SZABÓ B. 1996: Félrenyelés okozta elhullás hegyi récénél (Aythya marila). Túzok I (2): 89.

GYÖRGYPÁl Z. 1978: Madártani adatok a Barcsi Tájvédelmi Körzetből. - Mad. Táj. 3: 4-5.

GYulaı G. G. 1904: Adatok a Balaton madárfaunájához. - Aquila 11: 215-218.

HADARICS T. 1996a: Érdekes madármegfigyelések (havasi szürkebegy). - Túzok I(1): 49-53.

HADARICS T. 1996b: Érdekes madármegfigyelések (füstös réce). - Túzok 1(2): 93-100.

HaDARICs T. 1996c: Érdekes madármegfigyelések (kis csér). - Túzok 1(3): 133-141.

HADARICs T. 1996d: Érdekes madármegfigyelések (hàlászsas, parti lile, kốforgató, szólórigó, örvös rigó). - Túzok 1(4): 168-181.

HADARICS T. 1997a: Érdekes madármegfigyelések (sarki búvár, kis sólyom, erdei szalonka, szólőrigó). - Túzok 2(1): 38-47.

HADARıCS T. 1997b: Érdekes madármegfigyelések (apácalúd, halászsas, kis sólyom, erdei szalonka). - Túzok 2(2): 7l-82.

HADARICs T. 1997c: Érdekes madármegfigyelések (vándorsólyom, kis csér) - Túzok 2 (3): 115-126.

HADARICs T. 1997 d: Érdekes madármegfigyelések (halászsas). - Túzok 2(4): 140-160.

HADARICS T. 1998a: Érdekes madármegfigyelések (északi búvár, kis kárókatona, apácalúd, fekete réce, füstös réce, örvös bukó, kis sólyom, szőlórigó). - Túzok 3(1): 18-32. 
HAdarucs T: 1998b: Érdekes madármegfigyelések (üstökös réce). - Túzok 3(2): 67-81.

Hadarics T. 1998c: Érdekes madármegfigyelések (kis csér). - Túzok 3(3): 94-104.

HADARICS T. 1998d: Érdekes madármegfigyelések (kis sólyom). - Túzok 3(4): 168-185.

HADARICS T. 1999: Érdekes madármegfigyelések (erdei szalonka, szólórigó). - Túzok 4(1-2): 46-56.

HAJEk A. 1955: Kiskárókatona Somogyban. - Aquila 59-62: 374.

HAVRANEK L. 1995: Érdekesebb előfordulások. - Anser 1: 10-11.

HAVRANEK L. 1996a: Ludak (Anser) elófordulása a Balaton déli partján. - Anser 2: 52-59.

HAvirANEK L. 1996b: A Balaton déli partján clöforduló vízimadarak, 1995. - Anser 2: 32-37.

HAvranek L., SzABó B. \& SzÁSz S. 1995a: Balatoni madárvonulások az 1991-1994. években. -

Anser 1: 12-28.

HAVRANEK L., SZABÓ B. \& SZÁSZ S. 1995b: Ritka madárvendégek az irmapusztai halastavakon: a kenti csér (Sterna sandvicensis). - Anser 1: 41-42.

Homonnay, N. 1959a: Darázsölyv elófordulása Kaszópuštán. - Aquila 66: 270.

Homonnay, N. 1959b: Tövisszúró gébics mint kakukk dajkamadár. - Aquila 66: 278-279.

HoRvÁTH, L. 1960. Taxonomical studies on the yellow wagtails of Hungary (Motacilla flava L.). Acta Zool. 6(1-2): 117-124.

HoRVÁTH, Z. 2001 : A békászó sas (Aguila pomarina) Somogy megyei elófordulásáról. - Aguila (in press). HoRvÁTH, Z. \& NAGY, T. 1994: Keresztcső́rúek (Loxia curvirostra) Somogy megyében. - Mad. Táj. 2: 18.

HorvÁth, Z. FenYôsı, L. Pintér, A. \& TÖmÖSvÁRY, T. 2001: Fekete gólya állomány vizsgálata Belsố Somogyban (1983-2000). - Aquila (in press).

HuNYADVÁry B. 1979: Gólyát lốttek le Somogy megyében. - Búvár 34: 492.

JAKAB B. 1989: Az 1984. évi gólyaszámlálás összesített eredménye. - Mad. Táj. 1-2: 11-13.

JAKAB B.1991: Az 1989. évi gólyaszámlálás (Ciconia ciconia) értékelése. - Mad. Táj. 1-2: 3-4.

JAKAB B.1992a: Regionális fehér gólya (Ciconia ciconia) adatok összesítése az 1991. évból. - Mad. Táj. 2: 14-15.

JAKAB B.1992b: Az 1989. évi gólyaszámlálás (Ciconia ciconia) javított összesítése. - Mad. Táj. 2: 16.

JAKAB B. 1993: Az 1992. évi fehér gólya (Ciconia ciconia) adatok értékelése regionális felmérések alapján. - Mad. Táj. 2: 5-7.

KADA I. 1951: Kacagócsér Dél-Dunántúlon. - Aquila 55-58: 228.

KALOTÁs ZS. 1982: Jelentés az 1980. évi vetési varjú (Corvus frugilegus) állományfelmérésrôl. Mad. Táj. 3: 280-282.

KALOTÁs ZS. 1985: Elôzetes jelentés az 1984. évi vetési varjú (Corvus frugilegus) állományfelmérésról. - Mad. Táj. 2: 17-19.

KALOTÁs ZS. 1986: Adatok ragadozómadaraink táplálkozásához. - Mad. Táj. 3: 27-31.

KALOTÁs ZS. 1987: A gyöngybagoly (Tyto alba) 1985. évi országos állományfelmérésének eredményei. - Mad. Táj. 1-2: 7-11

KALOTÁS, ZS. 1988: Saatkrähen in Ungarn. Ein Vergleich der Jahre 1980 und 1984. - Beih. Veröff. Naturschutz Landschaftspflege Bad.-Württ. 53: 67-74.

KALOTÁs ZS. 1989: Adatok a macskabagoly (Strix aluco) táplálkozásához. - Mad. Táj. 1-2: 29-35.

KALOTÁs ZS. \& PINTÉR A. 1986: A gyöngybagoly fehér mellú alfajának (Tyto alba alba) újabb elöfordulásai a Dunántúlon. - Mad. Táj. 3: 10-11.

KASZA F. 1982a: Berki tücsökmadár (Locustella fluviatilis) megfigyelések, 1978-1981. - Mad. Táj. 2: $158-159$.

KASZA F. 1982b: Búbos cinege (Parus cristatus) és fenyvescinege (Parus ater) fészkelése 1981-ben Somogyszobon. - Mad. Táj. 3: 235-236.

KASZA F. 1983a: Voltak-e túzokok (Otis tarda) 1982-ben Dél-Somogyban. - Mad. Táj. 1: 34-35.

KASZA F. 1983b: Léprigó (Turdus viscivorus) nyári előfordulása Somogyszob környékén. - Mad.

Táj. I: 37.

KaSzA F. 1983c: A sisegö füzikék (Phylloscopus sibilatrix) terjeszkedése. - Mad. Táj. 1: 39.

KASZA F. 1983d: Berki tücsökmadár (Locustella fluviatilis) megfigyelések 1982-ben. - Mad. Táj. 2: 92-93.

KASZA F. 1984: A sisegő füzike (Phylloscopus sibilatrix) terjeszkedése. - Mad. Táj. l: 39.

KASZA F. 1987: Adatok a fekete gólya (Ciconia nigra) fészkeléséhez. - Mad. Táj. 3-4: 15.

KASZA F. \& MARIÁN M. 2001: A Baláta-láp és gerinces állatvilága, különös tekintettel a madarakra. - Natura Somogyiensis, Kaposvár (in print).

KÁRPÁTı L. 1977: Csörgó réce költése a darányi Nagyberekben. - Mad. Táj. 3: 1. 
Kárṕítı L. 1979: A Barcsi Ốsborókás madárvilága. - Somogyi Almanach 30: I-52.

KÁRPÁTI L. 1980: Herpeto és ornito ökofaunisztikai vizsgálatok a középrigóci (barcsi) borókásokban. - Erdészeti és Faipari Tudományos Közlemények 1: 83-91.

Keller O. 1936: Reznek a Balaton környékén. - Természettudományi Közlöny 68: $36-37$ (Pótfüzet).

KeLLER O. 1937: Daru a Balaton környékén. - Természettudományi Közlöny 69: 622-623.

KELLER O. 1937: Kúgyászölyv a Balaton környékén. - Természettudományi Közlöny 69: 38-40 (Pótfüzet).

KEVE A. 195 I: A fekete gólyák költése és vonulása 1949-ben Somogyban. - Aquila 55-58: 236.

KEVE A. 1954: A balkáni fakopáncs terjeszkedése a Dunántúlon. - Aquila 55-58: 299-310.

Keve A. 1973: A somogyi Balaton-part halastavainak madárvilága. - Somogyi Múzeumok Közleményei 1: 263-275.

Keve A. 1974: A Balaton sirályai. - Aquila 78-79: 107-132.

Keve A. 1975: Adatok az "Iszap" (Balatonberény) madáréletéhez. - Somogyi Múzeumok Közleményei 2: 155-161.

KEVE A. 1978: A Balaton déli partjának madárvilága. - Somogyi Múzeumok Közleményei 3: 461-501.

KEVE A. 1982: A Balaton szárcsaállományának összefüggése a rendelkezésre álló táplálékkal. - Állattani Közlemények 69: 119-121.

Keve A. 1983: A bukórécék jelentősége a Balaton életében. - Aquila 90: 105-112.

Keve, A. \& PÁtKAl, I. 1961: The ring ouzel in Hungary. - Acta Zool. 7(1-2): 185-190.

KIRÁlY I. 1957: Adatok a halászsas hazai fészkeléséhez. - Aquila 63-64: 270.

LÁszló I. 1996: Még egyszer kenti csér (Sterna sandvicensis). - Anser 2: 63.

LÁszló I., NovotNy ZS., PONGRÁCZ Z., SIMON P., SzABó B. \& ifj. Vincze B. 1996: A dél-balatoni régió fehér gólya (Ciconia ciconia Linné, 1758) állományának alakulása az 1996-os évben. - Anser 3: 41-49.

MaGYar G. 1997: Az MME Nomenclator Bizottság 1995. évi jelentése a Magyarországon ritka madárfajok előfordulásáról (kacagócsér). - Túzok 2(1): 1-10.

Magyar G., Hadarics T., WALICZKY Z., SCHMIDT A., Nagy T. \& BanKovics A. 1998: Nomenclator avium Hungariae. Magyarország madarainak névjegyzéke. - Madártani Intézet, MME, Winter Fair, Budapest-Szeged, p. 1-202.

MAJER J. 1992a: Boronka-melléki Tájvédelmi Körzet zoológiai felmérése (gerinces fauna) (19901991). - Dunántúli Dolg. Term. tud. Sorozat 7: 347-375.

MAJER J. 1992b: Baláta-tó zoológiai felmérése (különös tekintettel a madárfaunára) (1989-1990). - Somogyi Múzeumok Közleményei 9: 321-328.

Marí́N M. 1956: Adatok a fehér gólya (Ciconia c. ciconia L.) fészkelési viszonyaihoz Somogyban, 1956-ban. - Rippl-Rónai Múzeum Közleményei, Kaposvár, p. 1-6.

MARÍ́N M. 1957: A Baláta gerinces állatvilága. - Somogyi Almanach 1: 1-67.

MArLÁN M. 1958a: Madártani jegyzetek Somogyból. - Aquila 65: 306-307.

MARián M. 1958b: A Baláta ôsláp állatvilága. - Természettudományi Közlöny 89: 119-123.

MARIÁN M. 1959: A Baláta madárvilágáról. - Aquila 66: 211-215.

MArián M. \& PusKás L. 1985: A Barcsi Borókás Tájvédelmi Körzet madárállománya. - Dunántúli Dolg. Term. tud. Sorozat 5: 207-232.

Merész K. 1996: Csóka. - Anser 2: 60-62.

MinAlicz Á. 1996: Örvös galamb (Columba palumbus). - Anser 2: 45-46.

MME NOMENCLATOR BIZOTTSÁG 1998: Az MME Nomenclator Bizottság 1996. évi jelentése a Magyarországon ritka madárfajok elófordulásáról (füles vöcsök). - Túzok 3(2): 41-52.

MOLNÁR I. 1983: Bagolytáplálkozási adatok a Dunántúlról. - Mad. Táj. 2: 106-110.

MolNÁr L. 1982a: Gémtelepek Magyarországon - 1976-1980. Mad. Táj. I: 24-25.

MOLNÁR L. 1982b: Faunisztika (halászsas, erdei cankó, nagy sárszalonka, rozsdástorkú pityer, búbos cinege, szóloórigó). - Mad. Táj. 1: 60-74.

MOLNÁR L. 1982c: Faunisztika (halászsas, sarki búvár, kontyos réce, vándorsólyom, szürke cankó, heringsirály, kis sirály, csüllő, szőloórigó, rőtbegyú pityer, havasi pityer, kis lilik, hegyi réce). Mad. Táj. 2: 175-185.

MOLNÁR L. 1982d: Csonttollú (Bombycilla garrulus) előfordulások 1981-1982. telén. - Mad. Táj. 3: 237-239.

MoLNÁR L. 1982e: Nagy ôrgébics (Lanius excubitor) adatok 1981-ból. - Mad. Táj. 3: 239. 
MOLNÁR L. 1982f: Nagy örgébics (Lanius excubitor) adatok 1981-1982. teléról. - Mad. Táj. 3: 240.

MOLNÁr L. 1982g: Késői elófordulások (piroslábú cankó). - Mad. Táj. 3: 241.

MOLNÁR L. $1982 \mathrm{~h}$ : Faunisztika (sarki búvár, kis sólyom, erdei cankó, csüllö, réti fülesbagoly, szürke külloo, kormos varjú, búbos cinege, szóloórigó, örvös rigó, havasi pityer, ujjaslile, erdei cankó, kis sirály). - Mad. Táj. 3: 241-256.

MolnÁr L. 1983: Faunisztika (kontyos réce, szürke cankó, kis sirály, lócsér, nagy ớrgébics). - Mad. Táj. 1: 22-25.

MOLNÁR L. 1984a: Adatok a Faunisztikai Szakosztály irattárából VII. (havasi pityer, nagy örgébics). - Mad. Táj. 1: 40-44.

MOLNÁR L. 1984b: Faunisztika (északi búvár, sarki búvár, kontyos réce, hegyii réce, pchelyréce, vándorsólyom, ujjaslile, lócsér, kis csér). - Mad. Táj. 2: 104-110.

MOLNÁR L. 1984c: Adatok a Faunisztikai Szakosztály irattárából VIII. (kis sólyom, kis póling, tavi cankó, sarlós partfutó, kis sirály). - Mad. Táj. 1: 44-53.

MOLNÁR L. 1985: Adatok a Faunisztikai Szakosztály irattárából IX-XI. (szürke küllô, tüzesfejú királyka, kormos légykapó, sarki búvár, batla, kis sólyom, ujjaslile, tavi cankó, kis sárszalonka, dolmányos sirály, heringsirály, kis sirály, kontyos réce, füstös réce). - Mad. Táj. 1: 41-54.

MOLNÁR L. 1986: Kis sólyom (Falco columbarius) elófordulások az 1983-1985. évekból. - Mad. Táj. 3: 21-24.

MOLNÁr L. 1987a: Ujjaslile (Pluvialis squatarola) adatok 1985-ból. - Mad. Táj. 3-4: 45-46.

MOLNÁR L. I987b: Faunisztika (énekes hattyú, bütykös hattyú, kontyos réce, tavi cankó, kis sárszalonka, heringsirály, kis sirály, csüllô, kis csér). - Mad. Táj. 3-4: 58-72.

MolNÁR L. 1988a: Kis sirály (Larus minutus) előfordulások, 1984-1985. - Mad. Táj. 1-2: 50-52.

MOLNÁR L. 1988b: Faunisztika (sarki búvár, vörösnyakú vöcsök, ujjaslile, szürke küllö, búbos cinege, tüzesfejú királyka, kormos légykapó, rozsdástorkú pityer, havasi pityer, nagy ôrgébics, keresztcsórüí). - Mad. \áj. 1-2: 56-78.

MolNÁr L. 1992: Az MME Faunisztikai adattárából (1986) (ékfarkú halfarkas). - Mad. Táj. 2: 36-42.

M.O.K. 1895: Ornitho-faunisztikai adatok. - Aquila 2: 187-188.

NAGY L. \& PinTér A. 1994: Védett állatok Somogyban (gerincesek). - Múzeumi Tájékoztató (Kaposvár) 1: 21 -32.

NAGY S. 1991: A fehér gólya (Ciconia ciconia) állományfelmérése a Kaposvár-BöhönyeBalatonederics útvonalon. - Mad. Táj. 3-4: 6-7.

NÉMETH M. 1996: Adatok a Zselic ragadozómadár-faunájához. - Anser 3: 50-53.

Novotny ZS., SzABó B. \& VinCze B. 1995: Beszámoló az 1995. évi fehér gólya (Ciconia ciconia Linné, 1758) cenzusról. - Anser 1: 33-40.

Novotny ZS. 1996: A Látrányi Természetvédelmi Terület. - Anser 2: 49-51.

PINTÉr A. 1993: A fekete gólya (Ciconia nigra) állománya és védelmének lehetóségei Somogy megyében. - Szakdolgozat, PATE Georgikon Mezőgazdaságtudományi Kar, Keszthely, p. 1-25.

PURGER J. J. 1996: A Boronka-melléki Tájvédelmi Körzet keleti határvidékének (Somogy megye) kisemlós faunája, gyöngybagoly, Tyto alba (Scopoli, 1769) köpetek vizsgálata alapján. - Somogyi Múzeumok Közleményei 12: 299-302.

PURGeR J. J. 1997: A csokonyavisontai halastavak (Somogy megye) környékének kisemlös faunája, gyöngybagoly köpetek vizsgálata alapján. - Természetvédelmi Közlemények 5-6: 105-109.

Purger J. J. 1998a: A Dráva mente Magyarországi szakaszának madárfaunája (Aves). - Dunántúli Dolg. Term. tud. Sorozat 9: 441-463.

Purger J. J. 1998b: A Dráva mente Somogy megyei szakaszának kisemlós (Mammalia) faunája, gyöngybagoly Tyto alba (Scopoli, 1769) köpetek vizsgálata alapján. - Dunántúli Dolg. Term. tud. Sorozat 9: 489-500.

RéKÁsI J. 1975: MolnÁrfecskék (Delichon urbica) fészkelése a tihanyi komphajón. - Aquila 80. $81: 290$.

RÉTHY Zs. 1980: Magyar madártani bibliográfia. - A Békés megyei Tanács VB Környezet- és Természetvédelmi Bizottsága és a Megyei Tudományos Koordinációs Bizottság, Békéscsaba, p. 1-657.

SÁrA J. 1970a: Ornithological Observations in the Neighbourhood of Péterhida. - Aquila 76-77: 196.

SÁrA J. 1970b: Flock of Storks Feeding on a Burning Barley Stubble. Aquila 76-77: 187. 
SCHENK J. 1918: I. Vertebrata. Classis. Aves. In: Paszlavszky J (ed.): A Magyar birodalom állatvilága /Fauna Regni Hungariae/ - A K. M. Természettudományi Társulat, Budapest, p. 1-112.

STOLLMANN A., CSORBA G. \& MÉSZÁROS F. 1987: Karmazsinpirók (Carpodacus erythrinus) elöfordulása Somogyban. - Aquila 93-94: 314.

SzABó B. 1995: Címadó madarunk: a nyári lúd (Anser anser Linné, 1758). - Anser 1: 5-9.

SzABÓ B. 1996a: A somogyi Nagyberek partimadár költó- és vonuló állományának és élôhelyeinek helyzete napjainkban. - Partimadár 5: 68-72.

SzaBó B. 1996b: A kárókatona (Phalacrocorax carbo Linné, 1758). - Anser 2: 3-7.

SZABÓ B. 1996c: A balatoni madártani kutatások története. I. rész. - Anser, 2: 25-31.

SzaBó B. 1996d: A haris Crex crex Linné, 1758. - Anser 3: 2-8.

SzABó B. 1996e: A balatoni madártani kutatások törtẻnete. Il. rész: Keller Oszkár munkássága. Anser 3: 54-58..

SZALAI GY. 1955: Énekeshattyú Somogyban. - Aquila 59-62: 377.

SZALAY L. E. 1934: Reznek túzok. - Aquila 38-41: 367.

SZATORı J. 1984: Sarki lúd (Anas caerulescens) Siófokon. - Mad. Táj. 2: 98.

SZÁRI J. 1996: Kormoránkrízis. - Anser 2: 8-15.

SZEMERE L. 1951: Hollók fészkelése Gálosfán. - Aquila 55-58: 261.

SZÉCHENYI F. 1942: Fészkelési adatok Somogyból. - Aquila 46-49: 463.

SzIKLA G. 1895: Igen kedves történet (Bizalmas czinke). - Aquila 2: 189.

TeVely R. 1996: Beszámoló a STA I. Természetvédelmi táboráról. - Anser 2: 40-44.

TileSCH G. 1986a: MOLNÁRfecske (Delichon urbica) fészkében költó kék cinege (Parus caeruleus). - Mad. Táj. 1: 65.

TilesCH G. 1986b: Ablakpárkány alatt fészkelö barátcinege (Parus palustris). - Mad. Táj. 1: 65.

TilesCH G. 1986c: Ritkaságok a középrigóci erdôben. - Mad. Táj. 1: 57-58.

TiLesCH G. 1989: Egerészölyv (Buteo buteo) különös fészkelése. - Mad. Táj. 1: 41.

TÖMÖSVÁRY T. 1982a: Érdekes táplálkozási megfigyelések réti sasnál (Haliaeetus albicilla). - Mad. Táj. 2: 98-99.

TÖMÖSVÁRY T. 1982b: Veszélyben a somogyi fekete gólya (Ciconia nigra) állomány. - Mad. Táj. 3: 268-270.

TÖMÖSVÁRY T. 1995: A somogyi rétisas populáció alakulása a Rétisasvédelmi Program beindítása óta. - Boronkai Füzetek 1: 33-34.

TÖMÖSVÁRY T., FENYÖSI L. \& HORVÁTH Z. 2000: Törpevízicsibe (Porzana pusilla) elöfordulása Somogyfajsznál. - Aquila 105-106: 160.

UJVÁRY I. 1917: Madárvonulási adatok Somogyból. - Aquila 24: 255.

VASVÁru M. 1928: Pandion haliaetus adatok. - Aquila 34-35: 387.

VASVÁRI M. 1937: Nyári képek Magyarország madárvilágából (Hanság, Hortobágy, Dél-Somogy). - Debreceni Szemle. okt.-dec. p. 287-293.

VAsvŃRI M. 1942: Az 1939/40-es tél és a madárvilág. - Aquila 46-49: 340-351.

VINCZE B. 1996: A jégmadár (Alcedo atthis) elófordulása és költése az Irmapusztai halastavakon. - Anser 2: 47-48.

VÖRÖSS L. Zs. 1986: Fecskék korai gyülekezése. - Mad. Táj. 1: 66-67.

ZERGÉNYI A. 1934: A fekete harkály terjeszkedése Somogy megyében. - Aquila 38-41: 368. 


\section{The avian fauna of Somogy county, Hungary (Aves)}

\section{Jenö J. Purger, LÁszló FenYösi}

The work by SCHENK (1918) has been considered a milestone in Hungarian ornithology: it is a detailed overview of the evolution of avian studies and of bird species occurring in the Hungarian Empire. As its literature section clearly shows, nearly a century ago Schenk had to review just about 2000 articles so as to be able to compile that work. No wonder that he was referring to literature only in the section of historical overview. Even Schenk must have been guided by compromise, since in the species section he could not afford to mention all dates and locations of each and every observation. He did so only in the case of rarer species.

There has not been a comprehensive work written about the avifauna of Somogy county, thus the work by SCHENK (1918) can well be regarded as a starting point. In several cases of occurrence the author refers to a location in Somogy county or to the county as a whole. It has been possible to further increase our knowledge by looking at bibliographies (e.g. RÉTHY 1980), and other library reference material. The journal "Aquila" has been contributing to the fame of Hungarian ornithology and science in general for more than a century. Just like in the time of Ottó Herman, results of the most recent ornithological research and observations are published in its columns year after year. Neither could we ignore the rest of the journals (e.g. „Állattani Közlemények, Dunántúli Dolgozatok Természettudományi sorozat, Kócsag, Somogyi Almanach, Somogyi Múzeumok Közleményei“), because these also include quite a number of communications dealing with birds in the county. We have been witnessing the expansion of ornithology in the past decades, which has lead to a growing number of bird watchers. They have published their short communications firstly in the journal "Madártani Tájékoztató", than most recently in "Túzok", and "Anser". This increase is apparent also from the literature collected in the present study, since more than half of the publications were written in the 1980s and 1990s. It is also striking that before the 1950s shorter communications had been dominant. Later, however, lengthier papers were also produced about the birds of the southern coast of lake Balaton (e.g. HavraneK et al. 1995a; Keve 1973, 1975, 1978; SzABÓ 1996a), the Boronka region (e.g. Majer 1992a), lake Baláta, (e.g. Kasza \& Marián 200l; Majer 1992b; MARIÁN 1957; MARIÁN \& PuSKর́s 1985), the juniper woodlands at Barcs (e.g. FenYốsI 1993a, 2000; KÁRPÁTI 1979), and the Dráva lowlands (e.g. BANK 1998; FENYÖSI 1996, PURGER 1998a). Research works before present time used to concentrate on certain distinguished areas which are now legally protected. The majority of the studies were faunistical in nature, thus we did not need to be selective in this respect. However, it was not possible to eliminate compromise and selectiveness in our work, since the largeness and delimitation of the area (e.g. species observed on the surface of the water of lake Balaton) convey real difficulties. Neither could we ignore the fact that very little is known about the bird fauna of the Zselic hills and the Külsó - Somogy areas.

The primary objective of our studies has been to compile a list of birds occurring or having occurred in Somogy county. The scientific and common (Hungarian) names and the taxonomic order of the species followed those in 
the work by MAGYAR et al. (1998), so that the avifauna of the county can be compared any time with the Hungarian checklist. Besides the species names we also indicated the important literature sources (in an alphabetic order).

Based on data collected until present time, there is information on the occurrence of 284 bird species in Somogy county, which represents $76 \%$ of the Hungarian avifauna. We are aware that neither the list nor the bibliography can be viewed as final and complete, but we do hope that the work having been started will be continued, and the white patches will soon disappear from the map showing avian research activities in the county.

Author's address:

Dr. Jenô J. PURGer

University of Pécs, Faculty of Sciences

Institute of Biology, Department of

Zootaxonomy and Synzoology

H-7624 Pécs

Ifjúság útja 6.

HUNGARY

László FENYŐsI

H-7570 Barcs

Petôfi S. u. 10.

HUNGARY 